Eskişehir Osmangazi Üniversitesi iiBF Dergisi

Nisan 2020, C. 15, S. 1, $347-370$.

Başvuru : 13.12.2018

Kabul : :25.01.2020

\title{
Stratejik Yönetim Araştırmalarının Evrimi: Yaklaşımlar ve Mikro Görüşler Üzerinden Bir Değerlendirme
}

\author{
Mehmet Bağış ${ }^{1}$ \\ Oğuzhan Öztürk²
}

\begin{abstract}
Stratejik Yönetim Araştırmalarının Evrimi: Yaklaşımlar ve Mikro Görüşler Üzerinden Bir Değerlendirme

Öz

Bu çalışma, "stratejik yönetim araştırmaları nasıl evrilmiştir?" sorusuna cevap aramaktadır. Bu soru çerçevesinde stratejik yönetim disiplinin 1980-2018 yılları arasındaki tarihsel gelişim sürecinde etkisi olan Pozisyon Yaklaşımı, Kaynaklara Dayalı Yaklaşım ve Kaynaklara Dayalı Yaklaşımı tamamlayıcı (mikro) görüşler temelinde bir inceleme yapılmıştır. İnceleme yaklaşımların ve mikro-görüşlerin tarihsel oluşum sırası dikkate alınarak sistematik literatür incelemesi şeklinde gerçekleştirilmiştir. Çalışmayı belli bir çerçevede yürütebilmek adına, yaklaşımların ve mikro görüşlerin (1) teorik temelleri, (2) rekabet avantajının dayanakları ve (3) sürdürülebilirlik mekanizmalarına ilişkin açıklamaları çerçevesinde bir karşılaştırma yapılmıştır. Sonuçta stratejik yönetim alanının birleştirilmesine, iyileştirilmesine ve genişlemesine katkı sağlama potansiyeli olan teorik çerçeveler ve öneriler sunulmuştur.
\end{abstract}

Anahtar Kelimeler: Stratejik Yönetim, Yaklaşımlar, Mikro Görüşler, Sürdürülebilir Rekabet Avantajı, Tarihsel Evrim
The Evolution of Strategic Management Researches: An Evaluation on Approaches and Micro Views

Abstract

This study seeks to answer the question, "How have strategic management research evolved?" Within the framework of this question, an investigation has been made on the basis of the position view, the resourcebased view and the complementary (micro) views which have an impact on the historical development process of the strategic management discipline between 1980 and 2018. The review was carried out in the form of systematic resource review, taking into account the historical formation order of the approaches and microviews. In order to carry out the study within a certain framework, a comparison was made within the framework of three criteria: (1) theoretical foundations of approaches and micro views, (2) competitive advantage bases and (3) sustainability mechanisms. As a result, theoretical frameworks and suggestions have been made with the potential to contribute to the consolidation, improvement and expansion of the strategic management area.

Keywords: Strategic Management, Approaches, Micro Views, Sustainable Competitive Advantage, Historical Evolution

\section{Giriş}

Strateji tarihi incelendiğinde 1900'lü yıllara kadar Sun Tzu'nun Savaş Sanatı (Giles, 2013), İbni Haldun (2007)'un Mukkadime'si, Niccolo Machiavelli'nin Prens'i, Lev Nikolayeviç Tolstoy'un Savaş ve Barış’ı gibi eserlerin temel köşe taşlarını oluşturduğu görülecektir. Bu eserlerin yanında Carl Von Clausewitz'in Savaş Üzerine'si, Cantillon (1755)'un Genel Ticaret Üzerine Makalesi ve Ricardo (1821)'nun Politik Ekonomi ve Vergilendirmenin İlkeleri gibi çalışmaları da bu köşe taşları arasında sayılabilir. Bu eserlerden İbni Haldun'un Mukkadime'si ve Machiavelli'nin Prens'i devlet yönetimiyle ilgili stratejileri, Cantillon (1755)'un çalışması ticaretle ilgili girişimcilik stratejilerini ve Ricardo (1821)'nun çalışması ise ekonomik getirilerle ilgili açıklamaları ortaya koymuştur. Diğerleri ise daha çok askeri savaş stratejileri üzerine odaklanmışlardır.

\footnotetext{
${ }^{1}$ Dr., Toyotasa Acil Yardım Hastanesi, m.bagis33@gmail.com, Yazar ORCID bilgisi: http://orcid.org/0000-0002-33923376.

${ }^{2}$ Arş. Gör. Dr., Sakarya Üniversitesi, İşletme Fakültesi, İşletme Bölümü, oguzhanozturk@sakarya.edu.tr, Yazar ORCID bilgisi: http://orcid.org/0000-0001-7959-9535.
} 
1900'lü yıllara gelindiğinde doğrudan strateji kavramına vurgular yapmayan, ancak strateji kavramının kapsamında yer alan girişimcilik, rekabet, risk, belirsizlik ve kar gibi kavramları ele alan çalışmaların varlığı göze çarpmaktadır. Bu çalışmalar arasında Knight (1921), Schumpeter (1934; 1942), Chamberlin (1933) ve Robinson (1933) gibi yazarların incelemeleri yer almaktadır. 1950'li yıllara kadar süren bu çalışmalardan sonra stratejik yönetim alanında dört dönemin varlığından söz edilebilir (Barca, 2009). Bu dönemler modern stratejik yönetim düşüncesinin ortaya çıkışı (1950-1960), stratejik planlama (1960-1980), rekabet stratejileri (1980-1990) ve yetenekler (1990-2018) araştırma akımı şeklinde sıralanabilir.

Özellikle rekabet stratejileri ve yetenekler araştırma akımlarının ortaya çıktığı 1980'li ve 1990'lı yıllardan sonra stratejik yönetim alanı büyük bir gelişme göstermiştir. Bu gelişim sırasında stratejik yönetim disiplini sürdürülebilir rekabet avantajı olgusuna açıklama getirmek için çeşitli akademik disiplinlerden faydalanmıştır. Bu disiplinler arasında siyaset bilimi, ekonomi, psikoloji, sosyoloji, askeri strateji ve biyoloji bulunmaktadır (Barca, 2003: 2; Jemison, 1981: 607; Williamson, 1999: 1087).

Stratejik yönetim alanının bu disipliner gelişimiyle birlikte farklı yazarlar alanın gelişim örüntülerini incelemeye başlamışlardır. Bu bağlamda Bracker (1980) strateji kavramının stratejik yönetim alanındaki tarihsel gelişim örüntüsünü incelemiştir. Çalışma yapıldığı tarih itibariyle hem stratejik yönetim alanının gelişmeye başladığı hem de henüz Pozisyon Yaklaşımı (PY) gibi temel yaklaşımların bile ortaya çıkmadığı bir dönemde yapıımıştır. Ayrıca çalışma sadece strateji kavramındaki değişimlere odaklanırken alandaki konularla ilgili herhangi bir açıklama yapmamıştır. Stratejik yönetim araştırmalarının teorik ve metodolojik evrimini inceleyen Hoskisson vd. (1999) PY, Kaynaklara Dayalı Yaklaşım (KDY) ve Bilgi Temelli Görüş (BTG) şeklinde bir ayrıma giderek, bu yaklaşımlara katkı sağlayan teorileri ele almışlardır. Ancak yazarlar bu tarihlerde stratejik yönetim alanına girmiş olan Dinamik Yetenekler Görüşü (DYG), ilişkisel Görüş (IG) ve Dikkat Temelli Görüş (DTG) gibi mikro yaklaşımlara hiç değinmemişlerdir. Bunun yanında bu çalışma yapıldığı tarih itibariyle de Kurum Temelli Görüş (KTG) ve Eylem Temelli Görüş (ETG) gibi çalışmaları kapsamına alamamıştır. Alanın belki de köşe taşı niteliğindeki eserlerinden biri olan Mintzberg vd. (2001)'nin çalışması ise alana düşünce okulları çerçevesinde yaklaşmış ve alanda on düşünce okulunun varlığından söz etmişlerdir. Bu çalışmanın en önemli eksikliği farklı ülkelerdeki kurumların firma stratejileri üzerine etkileri ve uygulama olarak strateji çalışmalarını incelemekten uzak kalmasıdır.

Stratejik yönetim alanının evrimini değişim, seçilim ve tutunma çerçevesinde evrimsel bir perspektifle ele alan Herrmann (2005)'ın çalışması ise bilgi, öğrenme ve inovasyon kavramları ekseninde bir tartışma yaparak stratejik yönetim alanının yeni baskın paradigmalar yaratmadaki zorluklarına odaklanmıştır. Ancak yazar endüstri ve firma düzeyinde ele aldığı stratejik yönetim çalışmalarını kurumlar, uygulamalar, eylemler, firmalar arası ilişkiler ve bilişsel değişkenler açısından değerlendirmeye tabi tutmamıştır.

Stratejik yönetim alanını bibliyometrik analizler yaparak ele alan Ramos-Rodríguez ve RuízNavarro (2004) 1980-2000 yılları arasında stratejik yönetim alanının evrimini, Acedo vd. (2006) KDY altındaki Kaynak Temelli, Bilgi Temelli ve iliş̧kisel görüşleri, Ronda-Pupo ve Guerras-Martin (2012) ise 1962-2008 yılları arasında strateji kavramının evrim dinamiklerini incelemişlerdir. Anahtar sözcükler üzerinden 1980-2005 yılları arasında yaptıkları incelemeyle Furrer vd. (2008) ise rekabet stratejileri, uyum olarak strateji, firma düzeyinde strateji ve yöneticilerin stratejik rolü gibi konular üzerinden alana eğilmişlerdir. Alandaki evrimsel gelişimi incelemek adına bibliyometrik analizlerle yapılan bu dört çalışma, alanın yönüyle ilgili önemli açıklamalar 
yapmıştır. Fakat bu çalışmalar alanda ortaya çıkan mikro görüşler, bu mikro görüşlerin teorik temelleri, rekabet avantajı dayanakları ve sürdürülebilirlik mekanizmalarını anlamaktan uzak kalmışlardır.

Alanı kuşatıcı bir şekilde inceleyen Guerras-Martín vd. (2014) makro-mikro ve dışsal-içsel değişkenleri dikkate alarak hazırladıkları sarkaçta birçok mikro görüşü ele almışlardır. Buna rağmen DTG, iG ve ETG gibi mikro yaklaşımlara vurgu yapmamışlardır. Yine bir diğer kuşatıcı çalışmada McKiernan (2017) ise stratejik yönetim alanının tarihsel incelemesini planlama, uygulama, öğrenme, pozisyon ve kaynaklara dayalı okullarla sınırlı tutmuştur.

Konuyla ilgili Türkçe yazında Sarvan vd. (2003), Eryiğit (2013) ve Çubukçu (2018)'nun yaptıkları incelemeler, Mintzberg vd. (2001)'nin on düşünce okulu çerçevesinde konuya yaklaştıkları için stratejik yönetim alanının evrimine ilişkin yeni bir bilgi ortaya koyamamışlardır. Bu çalışmalara ek olarak, konuya Kuhn (2012)'un paradigma kavramı çerçevesinde yaklaşan Barca (2005) stratejik yönetim tarihine ve alanın disiplinleşme öyküsüne yönelik bir tartışma yürütmüştür. Bu çalışma da alandaki mikro görüşlere yönelik bilgiler vermekten uzak kalmıştır. Son olarak stratejik yönetim düşünce ve araştırmalarının Türkiye'deki entelektüel yapısını bibliyometrik analizlerle inceleyen Barca ve Hızıroğlu (2009)'nun çalışması sadece Türkiye bağlamıyla sınırlı kalmıştır.

Görüldüğü üzere, hem ulusal hem de uluslararası yazında stratejik yönetim disiplininin tarihsel evrimini, yaklaşımlar ve mikro görüşler çerçevesinde sistematik olarak (Molina Azorin, 2014: 103) inceleyen kuşatıcı bir çalışma bulunmamaktadır. Bu durum alanın içindeki ve dışındaki okuyucular açısından bir kafa karışıklığına sebep olmaktadır. Alandaki gelişmeler neticesinde ortaya çıkan yaklaşımların ve mikro görüşlerin alanda nerede durdukları ve bunların aralarındaki farklar araştırmacıların/okuyucuların işlerini zorlaştırmaktadır. Dolayısıyla bu çalışma stratejik yönetim alanında hem yaklaşımları ${ }^{3}$ hem de mikro görüşleri ${ }^{4}$ tarihsel olarak ortaya çıkış sırasına göre evrimsel olarak alana yaptıkları katkılar temelinde inceleyerek yukarıda sıralanan çalışmalardan ayrılmıştır. İnceleme 1980-2018 yılları arasında stratejik yönetim alanının tarihsel gelişim sürecinde etkisi olan PY (Porter, 1980, 1981), KDY (Barney, 1991; Wernerfelt, 1984) ve KDY'yi tamamlayıcı görüşler etrafında üç başlıkta gerçekleştirilmiştir. Bu sınıflandırmada KDY, Kaynak Temelli Görüş (KATG), BTG (Grant, 1996a; 1996b), DYG (Teece vd. 1997) ve İ (Dyer ve Singh, 1998; Lavie, 2006) şeklinde kendi içinde gelişen görüşler temelinde incelenmiştir. KDY'yi tamamlayıcı görüşler olarak ise ETG (Johnson vd., 2003; Whittington, 1996), DTG (Ocasio, 1997; Ocasio ve Joseph, 2005) ve KTG (Peng, 2002; Peng vd. 2009)'nin açıklamaları temel alınmıştır. Bu sınıflama sayesinde alanda dağınık halde bulunan mikro görüşler bir çerçevede toplanarak kategorize edilmiş ve alandaki dağınıklığın giderilmesi açısından bir adım atılmıştır.

Tablo 1: Yaklaşımlar ve Mikro Görüşler

\begin{tabular}{ccc}
\hline Pozisyon Yaklaşımı & Kaynakları Dayalı Yaklaşım & KDY'yi Tamamlayıcı Görüşler \\
\hline & Kaynak Temelli Görüş (KATG) & Eylem Temelli Görüş (ETG) \\
& Bilgi Temelli Görüş (BTG) & Dikkat Temelli Görüş (DTG) \\
& Dinamik Yetenekler Görüşü (DYG) & Kurum Temelli Görüş (KTG) \\
& İlişkisel Görüş (iG) & \\
\hline
\end{tabular}

\footnotetext{
${ }^{3}$ Burada "yaklaşım" kavramı tercih edilmiştir. Ancak "okul” kavramını kullanan çalışmalar da mevcuttur (Barca, 2005).

${ }^{4}$ Mikro görüşler kavramı, KDY'nin dinamik yetenekler, bilgi temelli görüş, ilişkisel görüş ve dikkat temelli görüş gibi görüşleri kapsayan şemsiye bir yapı (Baum ve Dobbin, 2000; Bağış ve Hızıroğlu, 2017; 2018) olarak kabul edilmesi nedeniyle kullanılmıştır.
} 
Stratejik yönetim disiplinindeki tarihsel evrimi incelemeyi amaçlayan böylesi bir çalışmayı belirli bir çerçevede tutabilmek için bir takım sorular temel alınmıştır. Zira stratejik yönetim yazınını böylesi bir çerçeveleme olmaksızın incelemeye tabi tutmak oldukça zor bir girişim olacaktır. Diğer bir ifadeyle bu çalışmadaki amaç, metaforik bir anlatımla, stratejik yönetim okyanusundaki dalgaları ortaya çıkış sırasına göre ve alana yaptıkları katkılar çerçevesinde incelemektir. Bu nedenle çalışmada ele alınan yaklaşım ve mikro görüşlerin her biri disiplinin cevap aradığı sorular çerçevesinde oluşturulan kriterler çerçevesinde bir incelemeye tabi tutulmuştur. Bu bağlamda stratejik yönetimin cevabını aradığı "Firmalar nasıl davranmaktadır?", "Firmalar arasındaki performans farklılıklarının nedenleri nelerdir?" (Barca, 2003: 18) ve "Niçin bazı firmalar başarılı, diğer firmalar başarısızdır?" gibi sorulardan hareketle çalışmayı çerçevelemekte şu kriterler kullanılmıştır: Yaklaşımların ve mikro görüşlerin (1) teorik temelleri, temel kavramları ve temel varsayımları, (2) rekabet avantajı dayanakları ve (3) sürdürülebilirlik mekanizmaları. Bu kriterler etrafında yapılan inceleme ile çalışma, stratejik yönetim araştırmalarının evrim örüntüleriyle ilgili bilgiler sağlamıştır. Dolayısıyla çalışma, okuyucuları stratejik yönetim araştırmalarının temelindeki varsayımlar ve odak noktalarla ilgili değişimler (Foss ve Hallberg, 2016), teorik temeller, temel kavramlar, temel varsayımlar, rekabet avantajı dayanakları ve sürdürülebilirlik mekanizmaları gibi konularda bilgilendirmeyi amaçlamaktadır.

\section{Stratejik Yönetim Alanındaki Yaklaşımlar}

\subsection{Pozisyon Yaklaşımı}

PY'yi Porter (1980, 1981)'ın çalışmaları oluşturmaktadır. Yaklaşım, endüstriyel organizasyon ekonomilerinden Yapı-Davranış-Performans (SCP) paradigması (Bain, 1956) üzerine temellenmiştir. Yapı (Structure), endüstrinin ekonomik ve teknik özelliklerini ifade etmektedir. Bu yapı firmaların kullandıkları fiyat, reklam, yetenek ve kalite gibi stratejileri veya davranışları (conduct) belirlemektedir. Firmaların kullandıkları stratejiler de firma performansını etkilemektedir. Performans ise karlılığı kapsamaktadır. Bu anlamda paradigma (Bain, 1956) endüstri yapısının firma stratejileri üzerindeki belirlenimci etkisinden dolayı statiktir ve yöneticilerin stratejik seçimlerini dikkate almamaktadır (Porter, 1981). Ancak sonraki çalışmalarda endüstri ve rekabetçi güçlerin incelenmesinde dinamik analizlerden yararlanılmıştır ve bu analizler yardımıyla endüstrilerin evrimi araştırılmıştır (Porter, 1981: 615; 1991: 113; Porter ve Spence, 1982: 260).

Yaklaşım üç varsayımdan hareket etmektedir. Bu varsayımlardan ilkine göre endüstride iyi bir konum elde etme firmalara rekabet avantajı sağlamaktadır. íkinci varsayıma göre bir endüstride rekabeti şekillendiren beş rekabetçi güçtür. Son varsayıma göre ise firmalar endüstri içinde rekabeti şekillendiren değişkenlere jenerik stratejilerle cevap vermektedir. Yaklaşıma göre sürdürülebilirliği sağlayan temel mekanizma firmanın endüstrideki konumunu giriş engelleriyle korumasıdır. Yaklaşımın referans aldığı giriş engelleri arasında; arz yönlü ölçek ekonomileri, talep yönlü ölçek ekonomileri, müşteri değişim maliyetleri, sermaye gereksinimleri, boyuttan bağımsız görev avantajları, dağıtım kanallarına ulaşımda eşitsizlik ve düzenleyici hükümet politikaları gibi değişkenler yer almaktadır (Porter, 2008a: 26-28).

PY'ye göre sektörün yapısını şekillendiren rekabetçi güçler beş başlıkta toplanmaktadır (Porter, 2008b: 27): Potansiyel rakipler, alıcıların/tedarikçilerin pazarlık gücü, ikame ürünlerin/hizmetlerin tehdidi ve endüstrideki mevcut rakipler arasındaki rekabet (Porter, 1989, 2008a). Dolayısıyla rekabet avantajı elde etmek isteyen bir firmanın başka firmaların giriş 
tehdidinin az, tedarikçilerin/müşterilerin pazarlık gücünün düşük, ikame ürünlerin, hizmetlerin ve yıkıcı rekabetin olmadığı endüstrilere yönelmesi gerekmektedir (Porter, 1991).

Yaklaşım, firmaların davranışlarını endüstrideki beş rekabetçi güçle açıklamaktadır. Bu güçler firmaların maliyet liderliği, farklılaşma ve odaklanma stratejilerini izlemelerine neden olmaktadır. Maliyet liderliği firmaların düşük maliyetli üretici olma yeteneğini, farklılaşma firmanın piyasada özgün olma becerisini ve odaklanma firmanın belirli bir konuda uzmanlaşma ve yoğunlaşma yetkinliğini ifade etmektedir. Bu stratejiler firmaların beş rekabetçi güçle rakiplerinden daha iyi baş edebilme yeteneğini göstermektedir (Porter, 1980).

Tablo 2: Yaklaşımların Belirlenen Kriterler Çerçevesinde Karşılaştırılması

\begin{tabular}{|c|c|c|c|c|}
\hline Yaklaşım & Teorik Temel & Rekabet Avantajının Dayanağı & $\begin{array}{c}\text { Sürdürülebilirlik } \\
\text { Mekanizması }\end{array}$ & Analiz Birimi \\
\hline $\begin{array}{l}\text { Pozisyon } \\
\text { Yaklaşımı }\end{array}$ & $\begin{array}{l}\text { SCP Paradigması } \\
\text { (Bain, 1956) }\end{array}$ & $\begin{array}{c}\text { - Çekici bir endüstri } \\
\text { - Endüstri içinde rekabetçi bir konum }\end{array}$ & Giriş engelleri & Endüstri, Firma \\
\hline $\begin{array}{l}\text { Kaynaklara } \\
\text { Dayalı } \\
\text { Yaklaşım }\end{array}$ & $\begin{array}{l}\text { Şikago okulu, } \\
\text { (Demsetz, 1973; } \\
\text { Penrose, 1959) }\end{array}$ & $\begin{array}{l}\text { - Statik: Firmaya özgü heterojen } \\
\text { kaynaklar } \\
\text { - Dinamik: Dinamik yetenekler }\end{array}$ & $\begin{array}{l}\text { Taklit engelleri } \\
\quad \text { (izolasyon } \\
\text { mekanizmaları) }\end{array}$ & $\begin{array}{c}\text { Firma (kaynaklar/ } \\
\text { yetenekler) }\end{array}$ \\
\hline
\end{tabular}

\subsection{Kaynaklara Dayalı Yaklaşım}

\subsubsection{Kaynak Temelli Görüş (Resource-Based View)}

Stratejik yönetim araştırmalarının hâkim yaklaşımı kabul edilen KATG, Wernerfelt (1984)'in çalışmasıyla ortaya çıkmıştır. Sonraki yıllarda Barney $(1986,1991)$ ve Peteraf $(1993)$ gibi araştırmacılar görüşün temel kavramları ve temellerini oluşturmuşlardır. Endüstriyel organizasyon ekonomilerinden Şikago Okulu üzerine temellenen görüş, getirilerin doğasının açıklanması anlamında Şikago Okulu ve Ricardocu ekonomilerden (neoklasik ekonomiler) yararlanmıştır. Şikago okuluna göre düşük maliyetlerle yapılan üretim, kaliteli ürünler ve firma ünü gibi firmaya özgü kaynaklar verimlilik getirileri sağlamaktadır (Demsetz, 1973: 2). Ricardocu ekonomiye göre ise getiriler nadir kaynaklara sahip olunması sonucu elde edilmektedir (Ricardo, 1821: 39-50). Bu bağlamda değerli toprak, konumsal avantajlar, patentler ve kopyalama haklarından elde edilen getiriler bu kapsamda değerlendirilmektedir (Mahoney ve Pandian, 1992: 364). Denge analizlerine ${ }^{6}$ dayanan bu görüş statik yaklaşım olarak da bilinmektedir.

KATG'ye göre rekabet avantajının dayanağı, stratejik faktör piyasalarındaki kaynakları diğer firmalardan daha etkili ve verimli şekilde elde etmek (Barney, 1986: 1231) ve bu kaynaklara sahip olmaktır. Görüşün temel varsayımına göre firmalar kendilerine özgü nadir, değerli, taklit ve ikame edilemez kaynaklara sahip olduklarında (Barney, 1991: 106) rekabet üstünlüğü elde edeceklerdir. KATG'nin diğer varsayımına göre ise bir endüstrideki kaynaklar firmalar arasında heterojen şekilde dağılmıştır ve sabittir (Barney, 1991: 112). Heterojenlik bazı firmaların diğer firmalara göre stratejilerini daha etkili şekilde geliştirmesine ve uygulamasına imkân sağlayan kaynaklara sahip olması olarak tanımlanırken, sabitlik kaynakların firmalar arasında rahatça transfer edilemezliğini ifade etmektedir. Görüş, özgün kaynaklara sahip olan firmaların rekabet avantajı elde edeceği argümanıyla stratejik yönetim alanına katkı sağlamıştır. KATG bu

\footnotetext{
${ }^{5}$ KDY'nin "statik" ve "dinamik" görüşleri arasındaki ayrıntılı açıklamalar için bakınız: Shulze, 1994: 38; Foss ve Stieglitz, 2012: 260.

${ }^{6}$ Ayrıntılı bilgiler için bakınız: Bağış ve Hızıroğlu (2018: 27-28)
} 
argümanıyla firma kaynak ve yetenek tabanındaki değişimleri ve yenilenmeleri dikkate almayarak önemli bir sınırlılık oluşturmuştur.

KATG'ye göre rekabet avantajının sürdürülebilirliği üç izolasyon mekanizmasıyla sağlanmaktadır. Bunlar tarih bağımlılığı (path dependent), nedensel belirsizlik (causal ambiguity) ve sosyal karmaşıklıktır (social complexity) (Barney, 1991: 107-110). Tarih bağımlılığı kaynakların özgün tarihsel koşullarla elde edilmesidir. Başka bir ifadeyle firmaların kaynakları elde etmesi ve bu kaynaklardan faydalanma yetenekleri belirli yer ve zaman (tarih) koşullarına bağlıdır. Nedensel belirsizlik ise bireylerin eylemleri ve sonuçları arasındaki nedensel bağlantıların doğasıyla ilgili belirsizlik durumunu ifade etmektedir (Lippman ve Rumelt, 1982: 418). Bu kavrama göre firmaya özgü kaynaklar ve sürdürülebilir rekabet avantajı arasındaki bağlantı diğer firmalar tarafından anlaşılamaz veya eksik şekilde anlaşılabilir (Reeds ve De Filippi, 1990). Firmaya özgü kaynaklar ve sürdürülebilir rekabet avantajı arasındaki bağlantı tam olarak anlaşılamadığı zaman kaynakların veya yeteneklerin taklit edilmesi zor veya imkânsız hale gelmektedir. Son olarak sosyal karmaşıklık müşterilerin, tedarikçilerin, yöneticilerin ve çalışanların kendi aralarındaki ilişkilerden ortaya çıkan karmaşık durumu ifade etmektedir (Reeds ve De Filippi, 1990: 91-92).

\subsubsection{Bilgi Temelli Görüş (Knowledge Based View)}

BTG ilk olarak Kogut ve Zander (1992) ve Nonaka (1994)'nın çalışmalarıyla ortaya çıkmıştır. Bu çalışmalarda Kogut ve Zander (1992) birleştirici yetenek kavramını ele almışlardır. Nonaka (1994) ise örgütsel bilgi oluşum teorisinin temel öğelerini ortaya koymuştur. Çalışmalarda Kogut ve Zander (1992) firma teorisine katkı temelinde bir tartışma yürütürken, Nonaka (1994) yeni bir teorinin (örgütsel bilgi oluşum teorisi) oluşum sürecine odaklanmıştır. Çalışmalar stratejik yönetim alanıyla doğrudan bir bağ kurmamakla birlikte örgütsel bilgi ve yetenekler kavramları çerçevesinde bilgi konusunu ele almışlardır.

Stratejik bir kaynak olarak bilgiye ilginin artması ve KATG'nin firma teorisi olduğuyla ilgili tartışmalar bilgi temelli görüş yazınının (Barney, 1996; Conner ve Prahalad, 1996; Foss, 1996a, 1996b; Grant, 1996a, 1996b; Kogut ve Zander, 1996; Liebeskind, 1996; Spender ve Grant, 1996) oluşmasını sağlamıştır. BTG'nin kavramları, varsayımları ve KATG arasındaki ilk bağlantı ise Grant (1996a)'ın çalışmasıyla oluşturulmuştur.

BTG, Firmanın Büyüme, Avusturyan Ekonomi, Evrimsel Ekonomi ve Örgütsel Öğrenme (Grant 1996a: 375-381; 1996b: 111) teorilerinden faydalanılarak geliştirilmiştir. Görüşün temel kavramları arasında örtük ve açık bilgi kavramları yer almaktadır. Örtük bilgi, doğrudan sahiplenilemeyen, transfer edilemeyen bir bilgidir. Bu bilgi insanların zihnine gömülü bir bilgi çeşididir (Polanyi, 1962: 601; 1967: 3). Bir işin nasıl yapıldığının öğrenilmesiyle ve bizzat tecrübe edilerek edinilir. Dolayısıyla bu bilgiye ustalık bilgisi de denilebilir. Ayrıca bu bilgi türü rekabetçi bir bilgidir. Buna karşılık açık bilgi ise kamusal ve rekabet değeri olmayan bir bilgi türüdür.

BTG'ye göre rekabet avantajının temel dayanakları entegrasyon verimliliği, entegrasyon kapsamı ve entegrasyon esnekliği kavramları üzerinden açıklanmaktadır (Grant, 1996a: 380). Entegrasyon verimliliği, firmanın örgüt üyelerinin sahip olduğu uzmanlık bilgisine erişme ve kullanma düzeyi olarak tanımlanmaktadır. Entegrasyon kapsamı ise bir örgütsel yetenek içinde kullanılan farklı uzmanlık alanlarına ait bilgilerin kapsamını ifade etmektedir. Son olarak entegrasyon esnekliğiyse bir örgütsel yeteneğin yeni bilgiye erişebilme ve mevcut bilgiyi yeniden yapılandırabilme özelliği şeklinde tanımlanmaktadır. 
Görüşün sürdürülebilirliği koruma mekanizmaları arasında özgün, transfer edilemeyen ve kopyalanamayan kaynak olarak bilgi yer almaktadır. Görüş dört varsayım üzerine temellenmiştir: 1-Üretimdeki kritik girdi ve öncelikli değerli kaynak bilgidir. 2-Bilgi açık ve örtük olmak üzere ikiye ayrılmaktadır. Örtük bilgi transfer edilmesindeki zorluklardan dolayı özellikle önemlidir. 3-Örtük bilgi bireyler tarafından uzmanlaşma yoluyla elde edilir ve bireylerde depolanır. 4-Üretim geniş bir bilgi yelpazesini gerektirir (Grant, 1996a: 385). Buraya kadar yazılanlar ekseninde görüşün alana temel katkısı örtük bilginin sürdürülebilir rekabet avantajı sağladığı iddiasıyla özetlenebilir. Bu iddia doğru olmakla birlikte görüş, kendisi dışındaki diğer değişkenlere kulak tıkayarak önemli bir sınırlılık hali ortaya koymaktadır. Örneğin görüş firmanın finansal yapısı, endüstrideki konumu, kaynak ve yetenek tabanındaki değişimleri, bulunduğu kurumsal bağlamın özellikleri, yöneticilerin karar alma yetkinlikleri, liderlikleri vb. gibi unsurlarla ilgili bir açıklama yapamamaktadır.

\subsubsection{Dinamik Yetenekler Görüşü (Dynamic Capabilities View)}

DYG ile ilgili araştırmalar Teece ve arkadaşlarının $(1994 ; 1997)$ çalışmalarıyla ortaya çıkmasına rağmen bu araştırma akımının ilk çalışmaları dinamik KATG'ye dayanmaktadır. Dinamik KATG ile ilgili çalışmalar Grant (1991), Mahoney ve Pandian (1992), Amit ve Schoemaker (1993) tarafından yapılmıştır. Bu yazarların çalışmalarında Evrimsel Ekonomi ve Firmanın Büyüme Teorilerinden yararlanarak firma yeteneklerini açıklamaları yaklaşımın dinamik yönelimini ortaya çıkarmıştır. Bu yönelim firma kaynak ve yetenek tabanındaki yenilenmeleri konu edinmektedir ve görüşün dengesizlik ${ }^{7}$ analizleri üzerine temellenmesini sağlamaktadır.

Görüş temelde iki yetenek kümesine değinmektedir: Bunlar dinamik yetenekler ve operasyonel yeteneklerdir. Dinamik yetenekler, firmaların yeni yetenekler oluşturma veya çevresel belirsizlik karşısında mevcut örgütsel yetenekleri yenileme ve dönüştürme becerileri olarak tanımlanmıştır (Teece vd., 1997: 518-521). Bu yetenekler yüksek düzey yeteneklerdir (Teece, 2012: 1) ve firmanın mevcut yetenek setinde yaptıkları değişikliklerle yenileyici (regenerative) dinamik yetenekler olarak da tanımlanmaktadır (Ambrosini vd., 2009: 2). Bu düzey yeteneklerin oluşturulmasında Evrimsel Ekonomi (Schumpeter, 1942; Nelson ve Winter, 1982) Firmanın Büyüme (Augier ve Teece, 2009: 410), Avusturyan Ekonomi (Foss vd., 2008: 73) ve Sosyal Ağ Teorilerinden (Blyler ve Coff, 2003: 678) faydalanılmıştır.

Operasyonel yetenekler ise bir firmanın geçmiş başarılarını tekrarlamak ve sürdürmek için gerekli olan süreçleri, prosedürleri ve becerileri öğrenerek ve iyileştirerek kaynak tabanında yararlandığı kapasitesini ifade etmektedir (Winter, 2003: 992). Bu yetenekler statik (Collis, 1994: 148), sıfır düzey (Winter, 2003: 992), ilk düzey (Danneels, 2002: 1114) ve sıradan yetenekler (Teece, 2014: 330) olarak da adlandırımaktadır. Bu düzeydeki yeteneklerin açıklanmasında, işlem maliyetleri, davranışsal karar (March ve Simon, 1958) ve firma davranışı teorilerinden (Cyert ve March, 1963) faydalanmıştır.

DYG, özünde üç varsayım üzerine temellenmiştir. Bunlar örgütsel yetenekler heterojendir ve transfer edilemezler (Schulze, 1994: 38), firmalar getiri arayışındadır ve sistematik olarak girişimsel getiriler elde edebilirler ve yöneticiler rasyonel seçimler yapmaktadır (Regner, 2008: 570) şeklinde sıralanabilir. Ancak görüş kapsamında yer alan sonraki çalışmalar farklı varsayımlar ortaya koymuştur. Bu varsayımlara göre dinamik yetenekler firma düzeyindeki örgütsel rutinler ve süreçler üzerine temellenmektedir (Eisenhardt ve Martin, 2000: 1107). Bu

\footnotetext{
${ }^{7}$ Ayrıntılı bilgi için bakınız: Bağış ve Hızıroğlu (2018: 27-28)
} 
yetenekler bilginin kodlanması ve eklemlenmesiyle koordine edilen geçmiş değişim süreçlerinin tekrarıyla öğrenilmektedir (Zollo ve Winter, 2002: 340). Yine bu yeteneklerin sabit ve öngörülebilir çevrelerdeki değişimleri açıkladığı kabul edilmektedir (Helfat ve Winter, 2011: 1246). Bir diğer varsayıma göre ise dinamik yetenekler örgütsel süreçler tarafından desteklenen alışkanlık haline gelmiş eylem örüntülerine dayanmaktadır. Son olarak bu yetenekler benzer durumların veya problem yapılarının tekrarlanmasıyla aktive edilen uygulamalar olarak kabul edilmektedir (Nelson ve Winter, 1982: 97).

$\mathrm{Bu}$ araştırma akımının alana temel katkısı firma kaynak ve yetenek tabanındaki değişime vurgu yapmasıdır. DYG firmalar arasındaki performans farklılıklarının nedenini ve rekabet avantajının temel dayanağını firmaya özgü varlıklar (ticarileştirilmesi zor bilgi varlıkları ve tamamlayıcı varlıklar) ve evrimsel süreçlerle şekillendirilen örgütsel yeteneklerle açıklamaktadır (Teece vd., 1997: 509). DYG'nin sürdürülebilirliği koruma mekanizmaları arasında ise özgün, tarih bağımlı, kopyalanması zor, nedensel belirsizlik ve sosyal karmaşıklık içeren örgütsel yetenekler yer almaktadır. Bu yetenekler, firmanın özgün varlık tabanını sürekli korumak, yenilemek, genişletmek ve yeniden yapılandırmak için kullanılmaktadır (Teece, 2007: 1341). DYG, firmaların kaynak ve yetenek tabanlarındaki değişime yönelik vurgularına rağmen, ilişkiye özgü ittifaklar ve yetenekler ve yeteneklerin kurumsal bağlamı gibi değişkenlerin stratejik olgulara yönelik açıklamalarını dikkate almayarak önemli bir sınırlıık hali ortaya çıkarmıştır.

\subsection{4. iliş̧kisel Görüş (Relational View)}

IG'ye Dyer ve Singh (1998), Gulati (1999) ve Lavie (2006)'nin çalışmalarının katkısı olmuştur. Görüş, sosyoloji temelli Sosyal Ağ Teorisi üzerine geliştirilmiştir (Lavie, 2006: 638). Son yıllarda yapılan çalışmalar ise görüşün evrimsel yaklaşımlarla incelenmesini sağlamıştır (Dyer vd., 2018). Sosyal ağ teorisinden ilişkisel bağlar kavramı ilişkisel getiriler ve yetenekler kavramının geliştirilmesini sağlamıştır (Bağış ve Hızıroğlu, 2018: 132). İlişkisel bağlar, iki örgüt arasında sermaye, para, insan kaynakları, bilgi, yedek parça ve teknoloji gibi somut ve soyut kaynakların ödünç alınması, ödünç verilmesi, alışı ve satışı gibi işlemlerin gerçekleştirilmesini sağlayan bağlardır (Wasserman ve Faust, 1994: 4).

IG, temelde iki varsayım üzerine oluşturulmuştur ve varsayımlar KDY'nin temel varsayımlarının firmalar arası ilişkilere taşınması sonucu ortaya çıkmıştır (Lavie, 2006: 638-640). Illk varsayıma göre firmalar arası ittifaklar sürdürülebilir rekabet avantajı elde edilmesini ve ilişkisel getiriler üretilmesini sağlamaktadır. İlişkisel getiriler firmadaki izolasyon mekanizmaları yardımıyla üretilemeyen, firmaya özgü ittifak ortaklıklarındaki değişim ilişkileri sonucu geliştirilen, ilişkilere özgü ve normalin üstündeki getirileri ifade etmektedir. İ'nin ikinci varsayıma göre ise firmalar arası ilişkiler sonucu geliştirilen kaynaklar ve yetenekler ilişkiye özgüdür. Bu sayede iG, ilişkisel getiriler ve ilişkisel getirilerin korunma yollarıyla ilgili bir çerçeve ortaya koyarak stratejik yönetim alanına katkı sağlamıştır. 
Tablo 3: KDY Altındaki Mikro Görüşler

\begin{tabular}{|c|c|c|c|}
\hline Görüşler & Teorik Temeller & $\begin{array}{c}\text { Rekabet Avantajının } \\
\text { Dayanağı }\end{array}$ & $\begin{array}{l}\text { Sürdürülebilirlik } \\
\text { Mekanizmaları }\end{array}$ \\
\hline $\begin{array}{l}\text { Kaynak Temelli Görüş } \\
\text { (Wernerfelt, 1984; Barney, } \\
\text { 1986; 1991; Peteraf, 1992) }\end{array}$ & Şikago Okulu (Demsetz, 1973) & $\begin{array}{l}\text { Kaynakları stratejik } \\
\text { faktör piyasalarından } \\
\text { elde etmek ve } \\
\text { kaynaklara sahip olmak }\end{array}$ & $\begin{array}{l}\text { Nadir, değerli, } \\
\text { taklit ve ikame } \\
\text { edilmesi zor } \\
\text { kaynaklar }\end{array}$ \\
\hline $\begin{array}{l}\text { Bilgi Temelli Görüş } \\
\text { (Grant, 1996a, 1996b; } \\
\text { Barney, 1996; Conner ve } \\
\text { Prahalad, 1996; Foss, 1996a, } \\
\text { 1996b; Kogut ve Zander, } \\
\text { 1996; Liebeskind, 1996; } \\
\text { Spender ve Grant, 1996) }\end{array}$ & $\begin{array}{l}\text { Firmanın Büyüme Teorisi (Penrose, } \\
\text { 1959); Avusturyan Ekonomi Okulu } \\
\text { (Hayek, 1945); Evrimsel Ekonomi } \\
\text { Teorisi (Nelson ve Winter, 1982); } \\
\text { Örgütsel Öğrenme Teorisi (Argyris ve } \\
\text { Schön, 1978) }\end{array}$ & $\begin{array}{l}\text { Entegrasyon verimliliği, } \\
\text { Entegrasyon kapsamı, } \\
\text { Entegrasyon esnekliği }\end{array}$ & $\begin{array}{l}\text { Taklit edilemeyen } \\
\text { örtük bilgi }\end{array}$ \\
\hline $\begin{array}{l}\text { Dinamik Yetenekler Görüşü } \\
\text { (Teece vd., 1997; Adner ve } \\
\text { Helfat 2003; Teece, 2007, } \\
\text { 2014, 2017; Helfat ve } \\
\text { Martin, 2015; Helfat ve } \\
\text { Peteraf, 2015; Helfat ve } \\
\text { Winter, 2011) }\end{array}$ & $\begin{array}{l}\text { Firmanın Büyüme Teorisi (Penrose, } \\
\text { 1959); Evrimsel Ekonomi Teorisi } \\
\text { (Nelson ve Winter, 1982); } \\
\text { Avusturyan Ekonomi Teorisi (Kirzner, } \\
\text { 1973); Sosyal Ağ Teorisi } \\
\text { (Granovetter, 1973, 1985; Burt, } \\
\text { 1992); Işlem Maliyetleri Teorisi } \\
\text { (Williamson, 1975); Firma Davranışı } \\
\text { Teorisi (Cyert ve March, 1963), } \\
\text { Davranışsal Karar Teorisi (March ve } \\
\text { Simon, 1958) }\end{array}$ & $\begin{array}{l}\text { Firmaya özgü varlıklar } \\
\text { ve evrimsel süreçler } \\
\text { tarafından } \\
\text { şekillendirilen örgütsel } \\
\text { yetenekler }\end{array}$ & $\begin{array}{l}\text { Taklit edilmesi zor } \\
\text { örgütsel yetenekler }\end{array}$ \\
\hline $\begin{array}{l}\text { Ilişkisel Görüş } \\
\text { (Dyer ve Singh, 1998; Gulati, } \\
\text { 1998; 1999; Gulati, Nohria, } \\
\text { ve Zaheer, 2000; Lavie, } \\
\text { 2006; Dyer, Singh ve } \\
\text { Hesterly, 2018) }\end{array}$ & $\begin{array}{l}\text { Sosyal Ağ Teorisi (Granovetter, 1973; } \\
\text { 1985, Burt, 1992) }\end{array}$ & $\begin{array}{lr}\text { İlişkiye özgü yatırımlar, } \\
\text { firmalar arası bilgi } \\
\text { paylaşım rutinleri, } \\
\text { tamamlayıcı } \\
\begin{array}{l}\text { zenginlikleri, } \\
\text { yönetişim }\end{array} \\
\end{array}$ & $\begin{array}{l}\text { İlişkiye özgü taklit } \\
\text { engelleri }\end{array}$ \\
\hline
\end{tabular}

Firmalar arası ittifaklar ürün, hizmet ve teknoloji geliştirmek amacıyla firmaların gönüllü olarak ilişkisel bağlar yardımıyla kaynak ve yetenek paylaşım sürecine girdiği işbirliğini ifade etmektedir (Gulati, 1998: 293). Bu işbirlikleri iki firma arasında olabileceği gibi, ikiden fazla firma arasındaki ağ ilişkilerinde de görülmektedir. İşbirlikleri ortak girişimler, satış tekeli hakkı (franchising), uzun dönem piyasa ve lisans sözleşmeleri, ticaret anlaşmaları, ar-ge ortaklıkları ve bağlanma (affiliation) gibi farklı formlar alabilmektedir (Lavie, 2006: 639). Firmalar bu ilişkiler sayesinde ilişkiye özgü yetenekler geliştirmektedir. Bu yetenekler ise rakipler için nedensel belirsizlik ve taklit engeli oluşturmaktadır.

IG'ye göre rekabet avantajı ve ilişkisel getiriler dört şekilde elde edilmektedir (Dyer ve Singh, 1998: 661). Bunlardan ilki firmalar arası ilişkiye özgü varlıklara ve işlemlere yatırım yapmaktır. Bu tür varlıklar, özgül varlıklardır. Bu varlıkların özgüllüğü yer, fiziksel varlık ve insan varlıklarının özgüllüğü olarak üçe ayrılmaktadır (Williamson, 1981: 555). Özellikle yer ve fiziksel varlık özgüllükleri farklı firmalarla işbirliklerini içeren yatırımlardır. Bu varlıklar işlem ve koordinasyon maliyetlerini azaltmaktadır ve ürün kalitesini iyileştirerek ilişkisel getiriler sağlamaktadır. Bu getiriler ilişkiye özgü yatırımların uzunluğuna (yıl) ve bu yatırımlara verilen güvencelere (safeguards) bağlıdır. Fırsatçıığa karşı güvence verecek uzunlukta tasarlanmış yönetimsel düzenlemeler, ittifak ortaklarının ilişkiye özgü varlıklara yatırım yapma yeteneklerini ve yüksek getiri elde etme potansiyellerini etkilemektedir. Ayrıca ittifak ortakları arasındaki ilişkilerin hacmi ve kapsamındaki büyüklük, ilişkisel getiri üretme potansiyelini arttırmakta ve rekabet avantajı sağlamaktadır. 
IG'ye göre rekabet avantajı ve ilişkisel getiri sağlayan ikinci husus firmalar arasında bilgi paylaşım rutinleridir (Dyer ve Singh, 1998: 664). Firmalar arasındaki bilgi paylaşım rutinleri firmaların birbirleriyle paylaştıkları bilgiyi, bu bilginin özümsenmesini, bu bilgiden yeni çıktılar üretilmesini sağlayan rutinlerdir. Bu tip bilgi paylaşım rutinleri firmalar arasındaki bilgi paylaşımını kolaylaştıracak teşvikler ve şeffaflı̆̆ı sağlayacak güven mekanizmaları ile işlem maliyetlerini azaltarak rekabet avantajına ve getirilere katkı sağlamaktadır.

Rekabet avantajı ve ilişkisel getiriler üreten üçüncü husus ise tamamlayıcı kaynak tabanlarıdır (Hamel ve Prahalad, 1996: 184). Buna göre ittifak ortakları birbirlerinin kaynak zenginliklerinden yararlanmaktadır. Nestle'nin marka adı ve Coca Cola'nın dağıtım kanallarını birleştirmesi bu tamamlayıcı kaynakların bir örneğidir. Son olarak etkili yönetim süreci rekabet avantajı ve ilişkisel getiri oluşturulmasında önemli bir rol oynamaktadır. Örneğin firmalar arası ilişkilerde işlem maliyetlerini arttıran formel ve bürokratik bir örgütlenme modeli yerine, informel, basit, esnek ve güvene dayalı bir modelin benimsenmesi (Williamson, 1975: 46-49) firmaların ilişkisel getirilerini arttırmasına ve rekabet avantajı elde etmesine olanak sağlamaktadır.

IG'ye göre sürdürülebilirlik ilişkiye özgü taklit engelleri sayesinde sağlanabilmektedir. Bu taklit engelleri ilişkiye özgü varlıklar, nadir ortaklıklar, kaynak/yetenek bölünmezliği veya sosyal karmaşıklık ve taklit edilmesi zor kurumsal çevrelerdir (Dyer ve Singh, 1998: 671). ilişkiye özgü varlıklara ilişkiye özgü yatırımlar sonucu oluşturulmuş tesisler ve donanımlar örnek olarak verilebilir. Bu yatırımların oluşturulmasında firmaların birlikte sarf ettikleri çabalar söz konusudur. Örneğin ana firma üretilecek parça için eğitim faaliyetleri yaparken, tedarikçi firma sermaye yatırımları yapabilir. Sürdürülebilirliği sağlayan ve ilişkiye özgü getirileri koruyan ikinci mekanizma ise nadir ortaklıklardır. Nadir ortaklıklar ilişkiye özgü yeteneklerin geliştirilmesiyle taklit edilmesi zor yeteneklerin oluşmasını sağlayabilir. Sürdürülebilirliği sağlama konusunda üçüncü mekanizma ittifak üyelerinin ilişkiye özgü ve özgün yetenekler geliştirerek kaynak bölünmezliğini sağlamasına vurgu yapmaktadır. Kaynak veya yetenek bölünmezliği firmaların birlikte geliştirdiği yeteneklerin hem ana firmanın hem de tedarikçi firmanın kontrolünde olduğu durumu ifade etmektedir. Son olarak ortaklar arasındaki güven ilişkilerini besleyen ve teşvik eden bir kurumsal çevre ilişkisel getirilerin üretilmesine, korunmasına ve sürdürülebilirliğin sağlanmasına yardımcı olmaktadır. Bu tip kurumsal çevreler resmi sözleşmeler (finansal teminatlar) yerine informel sözleşmelerin (güven ve iyi niyete dayalı) kullanılmasını sağlayarak sözleşme, uyum, kontrol ve işlem maliyetlerinin düşmesini sağlamaktadır (North, 1990: 68-69).

\subsection{Kaynaklara Dayalı Yaklaşımı Tamamlayıcı Görüşler}

\subsubsection{Eylem Temelli Görüş (Activity Based View)}

Uygulama olarak strateji çalışmaları Whittington (1996)'un çalışmasıyla ortaya çıkmıştır. Bu çalışmalar ETG (Jarzabkowski, 2005; Johnson vd., 2003) veya stratejinin uygulama temelli görüşü (Jarzabkowski vd., 2016) olarak da bilinmektedir. ETG, strateji çalışmalarının kara kutusuyla ilgilenmektedir. Diğer bir ifadeyle, bu çalışmalar bağlamsal uygulamalar tarafından sınırlanan (veya imkân sağlanan) bireysel eylemler üzerine odaklanmaktadır. Görüş, aktörlerin günlük stratejik eylemleri ve uygulamalarını stratejik yönetim alanına taşımıştır (Regnér, 2008: 569).

ETG'nin teorik temelleri felsefede faydacılık (pragmatizm), uygulamada sosyal teoriye dayanmaktadır. Pragmatik felsefede Derrida, Latour, Foucault ve Wittgenstein, sosyal teoride 
ise Pierre Bourdieu, Michel de Certeau, Foucault ve Giddens gibi yazarlar görüşe katkı sağlayan temsilcileri arasındadır (Golsorkhi vd., 2010: 1-2). Bu iki teorik yönelim kurumsal teori (bağlama gömülü eylemler), aktör ağ teorisi (birbirine bağlı eylemler), firma davranışı teorisi (örgütsel rutinler/yetenekler ve sezgi yeteneği) ve durumlu öğrenme (insanların günlük faaliyetleri) gibi teorilerin strateji olarak uygulama çalışmalarında kullanılmasını sağlamaktadır. Bu teoriler makro-mikro analiz düzeylerinde ve stratejinin içerik-süreç araştırmaları temelinde eylem temelli görüşün açıklamalarına yardımcı olmaktadır (Johnson vd. 2007: 37).

ETG'nin pratik (praxis), uygulama (practice), uygulayıcılar (practitioners) ve stratejik eylemler (strategizing) şeklinde dört temel kavramı bulunmaktadır (Whittington, 2006: 619620). Pratik, insan eyleminin tamamını tanımlamak için kullanılan bir terimdir (Reckwitz, 2002: 249) ve insanların pratikte yaptıkları gerçek aktiviteyi ifade etmektedir (Whittington, 2006: 615). Kavram farklı, dağınık halde bulunan bireylerin ve grupların eylemleri ile bireylerin rol aldığı ve katkıda bulundukları sosyal, politik ve ekonomik olarak gömülü kurumların eylemleri arasındaki bağlantıyı kapsamaktadır (Jarzabkowski vd., 2007: 9). Faaliyetler olarak da ifade edilen bu kavram stratejik planlamaları, formülasyonu ve uygulamaları kapsamaktadır. Uygulama ise birbirine bağlı ve farklı unsurlardan oluşan rutin davranış tipleri olarak tanımlanmaktadır. Bu davranış tipleri arasında bedensel ve zihinsel faaliyet biçimleri, nesneler ve nesnelerin kullanımı, duygusal ve motivasyonel bilgi durumları ve teknik bilgi (know-how) yer almaktadır. Görüşün üçüncü kavramı uygulayıcılarsa uygulamalar ve pratiklerle ilgili bireyleri ifade etmektedir. Diğer bir ifadeyle uygulayıcılar stratejinin aktörleri olarak hem faaliyetleri gerçekleştiren hem de uygulamaları yürüten stratejistlerdir (Whittington, 2006: 619). Son olarak stratejik eylemler, stratejinin yapılması olarak tanımlanmaktadır. Bu kavram farklı aktörlerin eylemleri, etkileşimleri ve uygulamaları sonucu oluşan faaliyet akışı şeklinde de ifade edilmektedir. Stratejik eylemler, faaliyetler, uygulayıcılar ve uygulamalar arasındaki ilişkiler arasında oluşmaktadır.

ETG, üç varsayımdan hareket etmektedir (Regner, 2008: 570). Ilk varsayıma göre yöneticiler ve çalışanlar sosyal ve kültürel uygulamalar tarafından sınırlanmış bir rasyonelliğe sahiptirler. $\mathrm{Bu}$ varsayım rasyonel ve sınırlı rasyonel (bilişsel ve dilsel sınırlar) aktör varsayımlarını tamamlayıcı bir özellik göstermektedir. İkinci varsayıma göre ise stratejik eylemler, farklı düzeylerdeki firma çalışanları ve yöneticileri arasında ve bu bireylerle dışsal aktörler arasında etkileşim sonucu ortaya çıkmaktadır. Son olarak stratejik eylemlerin sosyal ve kültürel bağlama gömülü olduğu kabul edilmektedir. Bu varsayım ise ekonomik bağlama gömülü stratejik eylemler varsayımını tamamlayıcı bir özellik göstermektedir.

Uygulama olarak strateji çalışmalarında rekabet avantajının dayanağı rutinlerdir (Practicesuygulamalar) (Jarzabkowski, 2004: 533). Bu kavram yetenekler kavramının temelindeki rutinlerdir. Bu anlamda görüş dinamik yetenekler araştırmalarını tamamlayıcı bir işlev görmektedir (Regnér, 2008: 565). Rutinler sosyal olarak karmaşık, firma içine gömülü ve birbirine bağı özelliktedir. Bunun yanında tarih ve bağlam bağımlı bir yapıya sahiptirler (Helfat vd., 2009: 7). Bu özellikleri firmanın örtük bilgisini içermesini ve firmanın örgütsel hafızası olarak işlev görmesini sağlamaktadır (Nelson ve Winter, 1982: 99-104). Rutinlerin bu özellikleri (Jarzabkowski, 2004) ve rutinlerle (uygulamalar-Practices) ilgili inovasyonlar (Jarzabkowski vd., 2016: 8) rekabet avantajının dayanakları olarak görülmektedir. ETG rekabet avantajının sürdürülebilirliğini ise taklit edilmesi zor, tarih ve bağlam bağımlı, nedensel belirsizlik içeren ve sosyal olarak karmaşık rutinlere (yeteneklere) bağlamaktadır. 


\subsubsection{Dikkat Temelli Görüş (Attention Based View)}

DTG, Ocasio (1997)'nun çalışmasıyla ortaya çıkmış ve sonrasında diğer çalışmalarla (Ocasio ve Joseph, 2005; Ocasio vd., 2017; Shepherd vd., 2017) geliştirilmiştir. Görüş, davranışsal karar teorisinden dikkat (Simon, 1947: 101-102) kavramı üzerine temellenmiştir. Dikkat örgüt üyelerinin hem sorunları (çevredeki problemler, fırsatlar ve tehditler) hem de bu sorunlara verilen cevapları (öneriler, rutinler, projeler, alternatifler, programlar ve süreçler) fark etmesi, kodlaması, değerlendirmesi ve belirli bir zaman veya çaba ile bunlara odaklanması olarak tanımlanmaktadır (Ocasio, 1997: 189). Görüşün stratejik yönetim alanına katkısı karar alma aşamasında örgütsel süreçlerin merkezine dikkati koymasıyla açıklanabilir (Carlsson, 2008). Bu bağlamda dikkatin odaklandığı bu örgütsel süreçler ile dinamik yeteneklerin bağlantısı göze çarpmaktadır. Bu özelliği nedeniyle görüş dinamik yetenekler araştırmalarını tamamlayıcı bir özellik göstermektedir (Ocasio ve Joseph, 2005: 56).

Firmanın rekabet avantajıyla ilgili kaynaklarına ve rekabetçi baskılar altında heterojenliği sürdürmesine kendi başına açıklama getiremeyen görüş, firmalar arasında heterojenliği sağlayan kaynakların açıklanmasına yardımcı olmaktadır. Diğer bir ifadeyle yöneticilerin örgütsel dikkati, dikkatin odaklandığı nokta ve yöneticilerin örgütsel dikkatini biçimlendiren yapılar heterojenliği oluşturan bir unsur olarak kabul edilmektedir. Bu bağlamda görüş sürdürülebilirlikle ilgili açıklamalar yapamamaktadır ve KATG'yi tamamlayıcı bir işlev görmektedir (Ocasio, 1997: 204-205).

DTG, yapı ve biliş arasındaki bağlantıya açıklama getirmeye çalışmaktadır. Diğer bir ifadeyle biliş, örgütsel yapı ve strateji formülasyonu arasındaki bağlantıları sağlayan ve firma davranışlarını açıklayan süreç temelli bir görüştür (Ocasio ve Joseph, 2005: 39). Bu anlamda DTG süreçler, iletişim kanalları ve dikkat yapılarıyla ilgili kavramlar aracılığıyla örgütsel yapıdaki davranışları ve bireysel bilgi işleme süreçlerini birbirine bağlayan bireysel, sosyal ve örgütsel olarak farklı analiz düzeylerinde açıklamalar yapmaktadır. Bu açıklamalar üç ilke veya öncülden hareket etmektedir (Ocasio, 1997: 189). Bireysel biliş düzeyinde dikkat odağı, bireysel biliş ve davranışlarla dikkat odağı arasında bağlantı kurmaktadır. Sosyal biliş düzeyinde, yerleşik dikkat karar alıcıların bulundukları bağlamın önemine vurgu yapmaktadır. Örgütsel düzeyde ise dikkatin yapısal dağılımı ilkesi, firmanın faaliyetleri ve karar alma bağlamının örgütsel süreçleri nasıl etkilediğini açıklamaktadır.

DTG, üç varsayımdan hareket etmektedir (Ocasio, 1997: 188). Bu varsayımlardan ilkine göre karar alıcıların eylemleri dikkatlerini odakladıkları konulara ve cevaplara bağlıdır. Diğer bir varsayıma göre ise karar alıcıların odaklandıkları konular ve eylemleri bulundukları bağlamdan etkilenmektedir. Son varsayıma göre ise karar alıcıların bulundukları bağlam ve bağlama katılımları; firma kuralları, sosyal ilişkiler düzeni, dikkat dağıtım kontrolü, konu ve cevap paylaşımı, faaliyetler, süreçler ve iletişim kanallarına bağlı olmaktadır. Görüşün temel bileşenleri ise altı başlıkta toplanmaktadır (Carlsson, 2008: 39-40). Bunlar karar çevresi, sorunlar ve cevaplar, süreçler ve iletişim kanalları, firmanın dikkat yapıları (oyunun kuralları, oyuncular, yapısal konumlar ve kaynaklar) karar vericiler ve firma davranışlarını kapsamaktadır. Bu bileşenler ve dikkat ile ilgili varsayımlar dikkate alındığında görüş, hem aktörü hem de yapısal unsurları dikkate alan açıklamalar yaparak stratejik yönetim alanına katkı sağlamaktadır.

\subsubsection{Kurum Temelli Görüş (Institutiton Based View)}

Kurum temelli görüş (KTG), firmalar arasındaki performans farklılıklarına ülkelerin kurumsal bağlamının ve kurumlarının açıklama getirebileceğini ileri sürmektedir (Peng vd., 2009). Görüş 
bu açıklamalarıyla stratejik yönetim alanına kurumlar, aktörlerin stratejik seçimleri ve örgütler arasındaki etkileşimleri dikkate alan bir çerçeve getirmiştir. KTG, Peng (2002); Peng vd., (2009) çalışmalarıyla stratejik yönetim alanına girmiştir. Teorik olarak davranışsal karar teorisi ve yeni kurumsal ekonomiler üzerine temellenmiştir. Görüş davranışsal karar teorisinden sınırlı rasyonellik, yeni kurumsal ekonomilerden ise formel ve informel kurumlardan yararlanmıştır (Peng vd., 2009: 66-67).

KTG'nin iki varsayımı bulunmaktadır. İlk varsayıma göre ekonomik aktörler, yöneticiler ve firmalar sınırlı (kasıtlı) rasyonel seçimler yapmaktadır. Ikincisi varsayıma göre ise yöneticilerin ve firmaların davranışları formel (hukuk, düzenlemeler ve kurallar) ve infomel (normlar, kültür ve etik) kurumlar tarafından sınırlandırılmaktadır (Peng vd., 2009: 66-67). Bu görüşün temel odağını farklı kurumlar, firmalar ve firma yöneticilerinin etkileşen stratejik seçimleri oluşturmaktadır. Burada kurumların firmalar ve yöneticiler üzerinde sınırlayıcı ve imkân sağlayıcı etkileri söz konusudur. Ayrıca endüstri koşullarıyla, firmaya özgü kaynaklar ve yeteneklerin yöneticilerin stratejik seçimleri ve firmalar üzerinde etkileri bulunmaktadır.

Görüş, rekabet avantajının dayanağını kurumsal bağlamdaki normatif rasyonellik, kurumsal izolasyon mekanizmaları ve eş biçimlilik baskılarını yönetebilme yeteneğine bağlamaktadır. Normatif rasyonellik firma yöneticileri ve çalışanlarının tarihsel, sosyal etkilerle sınırlanmış ve sosyal bağlamdan etkilenen seçimler yaptıklarını kabul etmektedir. Bu rasyonellik yöneticiler açısından bilişsel sınırlar üretmektedir. Bunun neticesinde yöneticilerin ve çalışanların kaynak ve yetenek kararları üzerinde güçlü kurumsal baskılar oluşmaktadır (Ginsberg, 1994: 156-158). Bu durum bilişsel batık maliyetler ortaya çıkarmaktadır ve geleneklerle uyumlu kararlar almayı beraberinde getirmektedir. Bilişsel batık maliyetler, firmanın ekonomik olarak yapılabilir alternatifleri araştırmasını engelleyen alışkanlıkları ve rutinleri değiştirmesiyle ilişkili sosyal ve psikolojik maliyetleri ifade etmektedir (Oliver, 1997: 702). Firma yöneticilerinin ve çalışanlarının bu gibi batık maliyetlerinin bulunması firma kaynaklarının ve yeteneklerinin değerlendirilmesiyle ilgili kararları olumlu veya olumsuz şekilde etkilemektedir. Dolayısıyla firmalar arasında normatif rasyonelliği yönetebilme yeteneğindeki farklılıklar rekabet avantajının önemli bir dayanağı haline gelmektedir.

Rekabet avantajının dayanağını oluşturan ikinci unsur kurumsal izolasyon mekanizmalarıyla ilgilidir (Oliver, 1997: 704). Bu mekanizmalarda kaynakların verimli kullanımıyla ve tedarikiyle ilgili kararlar sosyal bağlamdan olumsuz etkilenmektedir. Kurumsal izolasyon mekanizmaları kaynak/yetenek kararlarını destekleyen politik veya kültürel bağlamın zayıf olması olarak tanımlanmaktadır. Bu durum kaynakların ve yeteneklerin verimli şekilde kullanılmasını kısıtlamaktadır. Kurumsal izolasyon mekanizmaları firmanın kültürel veya politik bağlamından farklı kaynakları elde etmedeki veya taklit etmedeki isteksizliğinin sonucu olarak ortaya çıkan taklit engelleridir. Bu mekanizmaların yüksek olduğu yerlerde rekabet avantajı elde edilmesi, firmaların değer üretecek kaynakları elde etmesini sağlayacak gerekli politik ve kültürel unsurları harekete geçirme yeteneklerine bağlı olmaktadır. Bu politik ve kültürel unsurları iyi yönetme yetenekleri firmalar arasında heterojenlik göstermektedir. Bu durum da firmalar arasında rekabet avantajının önemli bir dayanağı olarak ortaya çıkmaktadır.

Rekabet avantajının dayanağı olan üçüncü unsur ise firmaların zorlayıcı, taklitçi ve normatif eş biçimlilik baskılarını yönetebilme yetenekleridir. Eş biçimlilik baskıları normalde firmalar arasında homojenlik üreten bir değişkendir (DiMaggio ve Powell, 1983: 150). 
Tablo 4: KDY'yi Tamamlayıcı Mikro Görüşler

\begin{tabular}{|c|c|c|c|}
\hline Görüşler & Teorik Temeller & $\begin{array}{c}\text { Rekabet Avantajının } \\
\text { Dayanağı }\end{array}$ & $\begin{array}{l}\text { Sürdürülebilirlik } \\
\text { Mekanizmaları }\end{array}$ \\
\hline $\begin{array}{l}\text { Faaliyet/Eylem Temelli Görüş } \\
\text { (Whittington, 1996, 2006; Johnson } \\
\text { vd., 2003, 2007; Jarzabkowski, } \\
\text { 2004; 2005; Gomez, 2010; } \\
\text { Mantere, 2013; Allard-Poesi, 2015; } \\
\text { De La Ville ve Mounoud, 2010) }\end{array}$ & $\begin{array}{c}\text { Durumlu Öğrenme Teorisi } \\
\text { (Lave ve Wenger, 1991); Firma } \\
\text { Davranışı Teorisi (Cyert ve } \\
\text { March, 1963); Aktör Ağ Teorisi } \\
\text { (Latour, 2005) Kurumsal Teori } \\
\text { (Meyer ve Rowan, 1977) }\end{array}$ & $\begin{array}{l}\text { Rutinler (uygulamalar) } \\
\text { ve rutinlerdeki } \\
\text { inovasyonlar }\end{array}$ & $\begin{array}{c}\text { Taklit edilmesi zor } \\
\text { rutinler }\end{array}$ \\
\hline $\begin{array}{c}\text { Dikkat Temelli Görüş } \\
\text { (Ocasio, 1997; Ocasio ve Joseph, } \\
\text { 2005; Ocasio vd., 2017; Shepherd } \\
\text { vd., 2017) }\end{array}$ & $\begin{array}{l}\text { Davranışsal Karar Teorisi } \\
\text { (Simon, 1947) }\end{array}$ & $\begin{array}{l}\text { Rekabet avantajının } \\
\text { kaynaklarını kendi } \\
\text { başına } \\
\text { açıklayamamaktadır }\end{array}$ & $\begin{array}{l}\text { Sürdürülebilirlik } \\
\text { konusunda } \\
\text { herhangi bir } \\
\text { açıklama } \\
\text { yapamamaktadır }\end{array}$ \\
\hline $\begin{array}{c}\text { Kurum Temelli Görüş } \\
\text { (Oliver, 1997; Peng, 2002; Peng } \\
\text { vd., 2009) }\end{array}$ & $\begin{array}{c}\text { Davranışsal Karar Teorisi } \\
\text { (Simon, 1947; Williamson, } \\
\text { 1975); Yeni Kurumsal } \\
\text { Ekonomiler (North, 1990) }\end{array}$ & $\begin{array}{l}\text { Kurumsal bağlamı } \\
\text { yönetebilme becerisi }\end{array}$ & $\begin{array}{l}\text { Kaynak sermayesi } \\
\text { ve kurumsal } \\
\text { sermaye }\end{array}$ \\
\hline
\end{tabular}

Özellikle düzenleyici baskılar, stratejik ittifaklar, insan kaynakları transferleri, rakiplerin teknolojilerinin taklit edilmesi veya rakipler arası kıyaslamalar bu homojenliği arttıran hususlardır (Oliver, 1997: 707). Ancak firmalar arasındaki getiri farklılıkları bu unsurların etkin bir şekilde yönetilmesiyle oluşmaktadır. Buraya kadar sayılan üç husus çevreden gelen kurumsal baskılara stratejik cevaplar verilmesini sağlayan (Oliver, 1991: 152) yetenekleri gerekli kılmaktadır. Dolayısıyla kurumsal baskıları yönetme yetenekleri ve bu baskılara verilen stratejik cevaplardaki farklılıklar firmalar arasında rekabet avantajını koruma veya kaybetme mekanizması olarak işlev görmektedir. KTG, sürdürülebilirlik mekanizmalarını ise kaynak sermayesi ve kurumsal sermaye (Oliver, 1997: 710) ile açıklamaktadır. Kaynak sermayesi, firmanın değer artıran kaynakları ve yetenekleri olarak tanımlanmaktadır. Kurumsal sermaye ise kaynak sermayesinin verimli bir şekilde kullanılmasını sağlayan bağlamsal faktörler olarak nitelenmektedir. Görüşle ilgili buraya kadar yapılan açıklamalar KATG'yi tamamlayıcı (Oliver, 1997: 697; Peng, 2002: 261) bir özellik göstermektedir.

\section{Tartışma ve Sonuç}

Incelenen her yaklaşım veya mikro görüş temelde firmalar arasındaki performans farklılıklarına, rekabet avantajı dayanaklarına, sürdürülebilirliği sağlayan ve engelleyen değişkenlere açıklama getirmektedir. Alanda bu kadar farklı yaklaşım veya mikro görüş bulunması alanın ekonomi, sosyoloji, psikoloji, politika ve biyoloji gibi disiplinlerle işbirliğinden kaynaklanmaktadır. Bu işbirlikleri stratejik yönetim alanı için kortiko steroid bir ilaç gibi işlev görmektedir. Bu ilaçlar bir dokuyu iyileştirirken, diğer dokularda hasar oluşturmaktadır. Benzer şekilde stratejik yönetim alanındaki farklı yaklaşım ve görüşlerin farklı teorik temellerden hareket etmesi de stratejik olguların açıklama gücünü arttırmaktadır. Ayrıca bu durum alanın gelişimi, alandaki bilginin evrimi ve alana paradigmatik bir çoğulculuğun hakim olması gibi kolaylıklar sağlamaktadır (Cannella ve Paetzold, 1994: 332). Ancak bu çoğulculuk alandaki yaklaşımların bütünlüğü, sağlamlığı, iyileştirilmesi ve birleştirilmesi gibi konuların ise ötelenmesine neden olmaktadır. Bu çalışmada alanın evrimi üzerine yapılan incelemede de bu zıtlık göze çarpmaktadır. Bu zıtlık alana hem bir parçalanmışlık hem de bir zenginlik görüntüsü vermektedir.

Tablo 2, 3 ve 4'te de görüleceği gibi, farklı teorik temeller mikro görüşlerin mikro-makro analiz düzeyilerinde ve firma içi-dışı değişkenler yardımıyla stratejik olguları açıklamaya 
çalıştığını göstermiştir. Bu açıklamalar özellikle BTG, DYG, IG, ETG, DTG ve KTG yazınlarında görülmektedir. Incelenen mikro görüşler kaynaklar, yetenekler, ittifaklar, ortak girişimler, piyasalar, endüstriler, kurumlar, uluslar gibi makro ve bireyler ve bireyler arası ilişkiler gibi mikro analiz düzeylerinde olguları ele almaktadır. Farklı analiz düzeyleri stratejik yönetim alanının verimliliğini sağlamaktadır ve farklı teorileri alana taşımaktadır. Ancak farklı teoriler temelinde yapılan ilerlemeler alanda varsayımlarla ilgili değişimleri gündeme getirmektedir. Bu varsayımsal değişimler genelde KDY (Foss ve Hallberg, 2016: 4-5; Bağış ve Hızıroğlu, 2017: 19) özelde ise dinamik yetenekler (Salvato ve Vassolo, 2018) yazınında görülmektedir. Ayrıca bu durum teorik temellerde tutarsızlıklar ve alanda parçalanmışlık riski ortaya çıkarmaktadır. Yine bu teorik çoğulculuk alanın sınırlarını belirsiz hale getirmektedir. Bu belirsizlik, alanın gelişiminde, üretiminde, canlılığında olumlu bir ivme sağlarken, bilimsel bilgi birikiminde çeşitlilik ve dağınıklık oluşturmaktadır.

Bahsi geçen çeşitlilik ve beraberinde getirdiği dağınıklık stratejik yönetim alanında bir berraklaşmadan ziyade bulanıklaşmayı beraberinde getirmektedir. Bu çalışmada yapılmak istenen tam olarak stratejik yönetim alanındaki yaklaşım ve mikro görüşlerin bu iç içe geçmişliğini ve her bir yaklaşım ve/veya mikro görüşün aynı şeyleri söylüyormuş gibi totolojik ifadelere yer vermesini ele almaktır. Bu açıdan çalışmada alandaki her bir yaklaşım ve mikro görüşün alanın temel sorunsallarına verdikleri cevaplar arasındaki farklılıkları rafine bir şekilde sunulmuştur. Alanın gidişatına ilişkin ifade edilen bu durumdan dolayı bu çalışmanın alana temelde iki açıdan katkı sağladığı söylenebilir: 1) stratejik yönetim alanının tarihsel gelişim sürecinde ortaya çıkan her bir yaklaşım ve mikro görüş arasındaki farkları ve benzerlikleri daha rafine bir şekilde sunma çabasında ortaya atılan sınıflandırma ve 2) her bir yaklaşım ve mikro görüşün alanın temel sorunsallarına verdiği cevaplar arasındaki ayrımı netleştirme çabası.

Bu yazılanlar ışığında stratejik yönetim alanında yukarıda sıralanan yaklaşımların ve mikro görüşlerin iyileştirilmesi için bir teoriye katkı sağlama veya teoriyi iyileştirmeyle ilgili rehber ilkelerin (Makadok vd., 2018) dikkate alınması gerekmektedir. Bu ilkeler arasında teorinin temel araştırma soruları, teorileştirme yöntemleri (nasıl), analiz düzeyleri (kim), olgunun bağlamı (nerede), nedensel mekanizmaları (niçin), yapıları veya değişkenleri (ne), teorinin sınırları (ne zaman), açıklamaları ve tahminleri yer almaktadır. Teorileştirme yöntemlerinden statikdinamik, süreç-içerik (değişken), tümevarımsal-tümdengelimsel, formel-informel ve analitiksayısal ayrımı çerçevesinde hangi yöntemin kullanıldığına dikkat edilmelidir. Analiz düzeyleri veya olgunun bağlamı anlamında ise yeni veya önceden gözden kaçırılan bir analiz düzeyi veya olgunun kullanılmaya başlanması, farklı analiz düzeyleri veya olguların mevcut teori içinde birleştirilmesi (Whetten vd., 2009: 2) gibi konuların sorgulanmasını gerektirmektedir. Ayrıca belirli bir olgu veya analiz düzeyine uygulanan bir teorinin faydası ve geçerliliği gibi konular irdelenmelidir.

Nedensel mekanizmalarla ilgili ise yeni bir nedensel mekanizmanın ele alınması, mevcut nedensel mekanizmaların faydası veya geçerliliğinin sorgulanması, nedensel mekanizmalar arasındaki benzerlikler veya farklıııkların ortaya konulması ve aracı (mediating) ve yönlendirici (moderating) değişkenler için çoklu nedensel mekanizmaların sentezi gibi konulara bakılması önem arz etmektedir. Örneğin algı, biliş, öğrenme, motivasyon vb. gibi psikolojik; uyum, sapkınlık, çatışma, sembolik etkileşim, güç ilişkileri, yapılanma vb. gibi sosyolojik; denge, rekabet, hile, işbirliği, pazarlık, esneklik, inovasyon, büyüme, stratejik eylemler, getiri arayışı vb. gibi ekonomik mekanizmalar arasındaki ayrımlara ve birleşimlere dikkat edilmelidir. 
Yapılar ve değişkenlerle ilgili olarak yeni bir yapının ele alınması, mevcut yapının geçerliliği veya faydasının sorgulanması, mevcut yapının daraltılması, iyileştirilmesi veya genişletilmesi gibi hususulara dikkat edilmelidir. Bunun yanında yapının rolüne ilişkin açıklamaların yapılması gerekmektedir. Teorinin sınır koşullarıyla (Bacharach, 1989: 499) ilgili ise mevcut teorilerin gizli (Barca, 2003: 53) veya örtük varsayımlarının ortaya çıkarılması, teorinin içsel tutarsızlıklarının (totoloji gibi) incelenmesi (Priem ve Butler, 2001b: 58), teoriler arasındaki mantıksal tutarsızlıkların tanımlanması, yeni uygulamalar için teorinin varsayımlarının yumuşatılması önem arz etmektedir. Ayrıca daha özgün etkiler ortaya çıkarmak amacıyla teorinin varsayımlarının sınırlanması ve teorinin çalışıp çalışmadığı zaman koşullarının bilinmesi gerekmektedir. Son olarak teorinin açıklamaları ve tahminleriyle ilgili yeni teoriden türetilen çıktılar, mevcut teoriden farklı şekillerde üretilen çıktılar ve teorilerin birleştirilmesi sonucu elde edilen sonuçların incelenmesi önem arz etmektedir.

$\mathrm{Bu}$ yazılanlar ekseninde stratejik yönetim alanının iyileştirilmesine ve birleştirilmesine yardımcı olacak teorik çerçeveler ${ }^{8}$ değer elde etme teorisi, gerçek seçim teorisi (Durand vd., 2017), mülkiyet hakları teorisi ve kurumsal kuram (Makadok vd., 2018) şeklinde sıralanabilir. Ayrıca yapılan incelemelerin sonunda stratejik yönetim araştırmalarında politika temelli incelemelere hala ihtiyaç duyulduğu göze çarpmaktadır. Bu eksende yapılacak araştırmalar kurum temelli görüş yazınıyla ilgili gelişmeler sağlayabilir. Bu incelemelerde gelecek araştırmaların şu sorulara cevap araması firmalar arasındaki performans farklılıklarının anlaşıımasına yardımcı olacaktır: Ülkelerde yaşanan politik istikrarsızlıkların ve belirsizliklerin firmaların performansına bir etkisi var mı? Firmaların devletle olan ilişkileri (Buğra, 2017) sürdürülebilir rekabet avantajını etkiler mi? Ülkelerin farklı ülkelerle yaşadıkları politik problemler ve gerilimler firmaların performansına nasıl yansımaktadır? Yine ülkelerin birbirlerine uyguladıkları ekonomik yaptırımların firma performanslarına bir etkisi var mıdır? Alanda sürdürülebilir rekabet avantajını açıklamada bu gibi sorulara yönelik bir ilginin oluşması stratejik yönetim disiplinin açıklama alanını genişletmek adına atılabilecek önemli bir adım olarak değerlendirilebilir. Disiplinin cevap aradığı sorulara yönelik açıklama getirmek için yukarıdaki sorularla yeni bir değişken olarak dikkate alınması önerilen "siyaset, politika, siyasi iktidar" gibi kavramların firmaların sürdürülebilir rekabet avantajı elde etmesine ne gibi etkilerinin olabileceği stratejik yönetim çalışmalarının başta kurumsal kuram olmak üzere diğer örgüt kuramları ile birleştirilmesine yönelik bir yönelime de işaret etmektedir. Nitekim bir alandaki/kuramdaki/disiplindeki mevcut açıklamaların genişletilebilmesi için kullanılan en önemli araçlardan birisi alternatif potansitel yazın ve/veya açıklama alanlarına başvurmaktır (Eisenhardt, 1989: 544-548). Bu sayede stratejik yönetim disiplininin alternatif yazınlar ile benzeşen/çelişen yönleri incelenerek sürdürülebilir rekabet avantajı ile ilgili bugüne dek hiç sorgulanmayan, dikkate alınmayan değişkenler aracılığıyla disiplinin açıklamaları güçlendirilecektir.

\footnotetext{
${ }^{8}$ Ayrıntılı bilgi için Strategic Management Journal’ın sayılarına bakınız: Volume 39, Issue 6, Special Issue, Volume 39, Issue 3, Special Issue, Volume 38, Issue 1, Special Issue
} 


\section{Kaynaklar}

Acedo, Francisco Jose; Barroso, Carmen; Galan, Jose Luis (2006), The resource-based theory: Dissemination and main trends. Strategic Management Journal, 27(7), 621-636.

Adner, Ron; Helfat, Constance E. (2003), Corporate effects and dynamic managerial capabilities. Strategic Management Journal, 24(10), 1011-1025.

Allard-Poesi, F. (2015), A Foucauldian perspective on strategic practice: strategy as the art of (un) folding. Golsorkhi, L. Rouleau, D. Seidl et E. Vaara (Eds.), Strategy as Practice, Theory, Epistemology, Methodology, 2nd ed., Cambridge : Cambridge University Press: 234- 248.

Ambrosini, Véronique; Bowman, Cliff; Collier, Nardine (2009), Dynamic capabilities: an exploration of how firms renew their resource base. British Journal of Management, 20, 9-24.

Amit, Raphael; Schoemaker, Paul J. H. (1993), Strategic Assets and Organizational Rent. Strategic Management Journal, 14(1), 33-46.

Argyris, Chris; Schön, Donald. (1978), Organizational Learning, Readings: Addison-Wesley Publishing Company.

Augier, Mie; Teece, David J. (2009), Dynamic capabilities and the role of managers in business strategy and economic performance. Organization science, 20(2), 410-421.

Bacharach, Samuel B. (1989), Organizational theories: Some criteria for evaluation. Academy of Management Review, 14(4), 496-515.

Bağış, Mehmet; Hızıroğlu, Mahmut (2017), Stratejinin kaynaklara dayalı yaklaşımına yönelik eleştirilere dair kategorik bir inceleme. Journal of Interpretation Management and Method, 5(1), 1-27.

Bağış, Mehmet; Hızıroğlu, Mahmut (2018), Stratejik Yönetim'in Kaynaklara Dayalı Yaklaşımı: Ekonomik, Sosyolojik, Psikolojik Temeller. Ankara: Nobel Akademik Yayıncılık.

Bain, Joe S. (1956), Barriers to new competition: Their character and consequences in manufacturing industries. Harvard University Press Cambridge, MA.

Barca, Mehmet (2003), Economic foundations of strategic management: Gower Publishing, Ltd.

Barca, Mehmet (2005), Stratejik yönetim düşüncesinin evrimi: Bilimsel bir disiplinin oluşum hikayesi. Yönetim Araştirmalari Dergisi, 5(1), 7-38.

Barca, Mehmet (2009), Stratejik yönetim düşüncesinin gelişimi. Ankara Sanayi Odası Dergisi, 34-52.

Barca, Mehmet; Hızıroğlu, Mahmut. (2009), 2000'li Yıllarda Türkiye'de Stratejik Yönetim Alanının Entelektüel Yapısı. Eskişehir Osmangazi Üniversitesi IïF Dergisi, 4(1), 113-148.

Barney, Jay B. (1986), Strategic factor markets: Expectations, luck and business strategy. Management Science, 32(10), 1231-1241.

Barney, Jay B. (1991), Firm resources and sustained competitive advantage. Journal of Management, 17(1), 99120.

Barney, Jay B. (1996), The resource-based theory of the firm. Organization Science, 7(5), 469-469.

Baum, Joel A.C..; Dobbin, Frank (2000), Economics meets sociology in strategic management, Greenwich: CT: JAI Press.

Blyler, Maurenn; Coff, Russell W. (2003), Dynamic capabilities, social capital, and rent appropriation: Ties that split pies. Strategic Management Journal, 24(7), 677-686.

Bracker, Jeffrey (1980), The historical development of the strategic management concept. Academy of Management Review, 5(2), 219-224.

Buğra, Ayşe. (2017), Devlet ve işadamları: Illetişim Yayınları.

Burt, Ronald S. (1992), Structural Holes: The social structure of competition. Cambridge, Massachusetts and London, England: Harvard University Press.

Cannella Jr, Albert A.; Paetzold, Romano L. (1994), Pfeffer's barriers to the advance of organizational science: A rejoinder. Academy of Management Review, 19(2), 331-341.

Cantillon, Richard (1755), An Essay on Commerce in General. History of Economic Thought Books.

Carlsson, Sven A. (2008), An Attention-based view on DSS. Encyclopaedia of Decision Making and Decision Support Technologies, F. Adam and P. Humphreys Eds., Idea Publishing Group, Hershey: 38-45.

Chamberlin, Edward H. (1933), The Theory of Monopolistic Competition: Harvard University Press, Cambridge, MA. 
Collis, David J. (1994), Research note: How valuable are organizational capabilities. Strategic Management Journal, 15(8), 143-152.

Conner, Kathleen R.; Prahalad, C. K. (1996), A resource-based theory of the firm: Knowledge versus opportunism. Organization Science, $7(5), 477-501$.

Cyert, Richard M.; March, James G. (1963), A behavioral theory of the firm, New Jersey: Prentice-Hall, Inc.

Çubukçu, Murat (2018), Stratejik yönetimin gelişim süreci ve stratejik yönetime dair literatürdeki güncel araştırma konularının sınıflandırılması. Stratejik Yönetim Araştırmaları Dergisi, 1(2), 61-84.

Danneels, Erwin (2002), The dynamics of product innovation and firm competences. Strategic Management Journal, 23(12), 1095-1121.

De La Ville, Valérie-Inès; Mounoud, Eléonore (2010), A narrative approach to strategy as practice: strategy making from texts and narratives. Cambridge Handbook of Strategy as Practice: 183-197.

Demsetz, Harold (1973), Industry structure, market rivalry, and public policy. Journal of Law and Economics, 16(1), 1-9.

Dierickx, Ingemar; Cool, Karel (1989), Asset stock accumulation and sustainability of competitive advantage. Management Science, 35(12), 1504-1511.

DiMaggio, Paul J.; Powell, Walter W. (1983), The iron cage revisited: Collective rationality and institutional isomorphism in organizational fields. American Sociological Review, 48(2), 147-160.

Durand, Radolphe; Grant, Robert M.; Madsen, Tammy L. (2017), The expanding domain of strategic management research and the quest for integration. Strategic Management Journal, 38(1), 4-16.

Dyer, Jeffrey H.; Singh, Harbir (1998), The relational view: Cooperative strategy and sources of interorganizational competitive advantage. Academy of Management Review, 23(4), 660-679.

Dyer, Jeffrey H.; Singh, Harbir; Hesterly, William S. (2018), The relational view revisited: A dynamic perspective on value creation and value capture. Strategic Management Journal, 39(12), 3140-3162.

Eisenhardt, Kathleen M. (1989), Building theories from case study research. Academy of Management Review, 14(4), 532-550.

Eisenhardt, Kathlen M.; Martin, Jeffrey A. (2000), Dynamic capabilities: what are they? Strategic Management Journal, 21(10-11), 1105-1121.

Eryiğit, Burak Hamza (2013), Stratejik Planlama, Stratejik Planlamaya Illişkin Alternatif Yaklaşımlar ve Stratejik Yönetim Okulları. Süleyman Demirel Üniversitesi Vizyoner Dergisi, 4(9), 152-173.

Foss, Nicolai J. (1996a), Knowledge-based approaches to the theory of the firm: Some critical comments. Organization Science, 7(5), 470-476.

Foss, Nicolai J. (1996b), More critical comments on knowledge-based theories of the firm. Organization Science, 7(5), 519-523.

Foss, Nicolai J.; Hallberg, Niklas L. (2016), Changing assumptions and progressive change in theories of strategic organization. Strategic Organization, 1-13.

Foss, Nicolai J.; Klein, Peter. G.; Kor, Yasemin. Y.; Mahoney, Joseph T. (2008), Entrepreneurship, subjectivism, and the resource-based view: toward a new synthesis. Strategic Entrepreneurship Journal, 2(1), 73-94.

Furrer, Olivier; Thomas, Howard; Goussevskaia, Anna (2008), The structure and evolution of the strategic management field: A content analysis of 26 years of strategic management research. International Journal of Management Reviews, 10(1), 1-23.

Giles, Lionel (2013), Sun Tzu on the Art of War. New York, Berlin: Taylor and Francis, Globusz Publishing.

Ginsberg, Ari (1994), Minding the competition: From mapping to mastery. Strategic Management Journal, 15(Winter Special Issue), 153-174.

Golsorkhi, Damon; Rouleau, Linda; Seidl, David; Vaara, Eero (2010), Cambridge handbook of strategy as practice: Cambridge University Press.

Gomez, Marie-Leandre (2010), A Bourdieusian perspective on strategizing. Cambridge Handbook of Strategy as Practice: $141-154$.

Granovetter, Mark S. (1973), The strength of weak ties. American Journal of Sociology, 78(6), 1360-1380.

Granovetter, Mark S. (1985), Economic action and social structure: The problem of embeddedness. American Journal of Sociology, 91(3), 481-510. 
Grant, Robert M. (1991), The resource-based theory of competitive advantage: implications for strategy formulation. California Management Review, 33(3), 114-135.

Grant, Robert M. (1996a), Prospering in dynamically-competitive environments: Organizational capability as knowledge integration. Organization Science, 7(4), 375-387.

Grant, Robert M. (1996b), Toward a knowledge-based theory of the firm. Strategic Management Journal, 17(2), 109-122.

Guerras-Martín, Luis Áangel; Madhok, Anoop; Montoro-Sánchez, Ángeles (2014), The evolution of strategic management research: Recent trends and current directions. Business Research Quarterly, 17(2), 69-76.

Gulati, Ranjay. (1998), Alliances and networks. Strategic Management Journal, 19(4), 293-317.

Gulati, Ranjay. (1999), Network location and learning: The influence of network resources and firm capabilities on alliance formation. Strategic Management Journal, 20(5), 397-420.

Gulati, Ranjay; Nohria, Nitin; Zaheer, Akbar (2000), Strategic networks. Strategic Management Journal, 21(3), 203215.

Haldun, İbni (2007), Mukaddime, Cilt I, Hazırlayan: Süleyman Uludağ, 5. Baskı, İstanbul: Dergah Yayınları.

Hayek, Friedrich A. (1945), The use of knowledge in society. The American Economic Review, 35(4), 519-530.

Helfat, Constance E.; Finkelstein, Sydney; Mitchell, Will; Peteraf, Margaret; Singh, Harbir; Teece, David J.; Winter, Sidney G. (2009), Dynamic capabilities: Understanding strategic change in organizations: John Wiley and Sons.

Helfat, Constance E.; Martin, Jeffrey A. (2015), Dynamic managerial capabilities: Review and assessment of managerial impact on strategic change. Journal of Management, 41(5), 1281-1312.

Helfat, Constance. E.; Peteraf, Margaret A. (2015), Managerial cognitive capabilities and the microfoundations of dynamic capabilities. Strategic Management Journal, 36(6), 831-850.

Helfat, Constance. E.; Winter, Sidney. G. (2011), Untangling dynamic and operational capabilities: Strategy for the (N) ever-changing world. Strategic Management Journal, 32(11), 1243-1250.

Herrmann, Pol (2005), Evolution of strategic management: The need for new dominant designs. International Journal of Management Reviews, 7(2), 111-130.

Hoskisson, Robert E.; Hitt, Michael A.; Wan, William P.; Yiu, Daphne (1999), Theory and research in strategic management: Swings of a pendulum. Journal of Management, 25(3), 417-456.

Jarzabkowski, Paula (2004), Strategy as practice: recursiveness, adaptation, and practices-in-use. Organization Studies, 25(4), 529-560.

Jarzabkowski, Paula (2005), Strategy as practice: An activity based approach: Sage.

Jarzabkowski, Paula, Balogun, Julia; Seidl, David (2007), Strategizing: The challenges of a practice perspective. Human Relations, 60(1), 5-27.

Jarzabkowski, Paula; Kaplan, Sarah; Seidl, David; Whittington, Richard (2016), On the risk of studying practices in isolation: Linking what, who, and how in strategy research. Strategic Organization, 14(3), 248-259.

Jemison, David B. (1981), The importance of an integrative approach to strategic management research. Academy of Management Review, 6(4), 601-608.

Johnson, Gerry; Langley, Ann; Melin, Leif; Whittington, Richard (2007), Strategy as practice: research directions and resources: Cambridge University Press.

Johnson, Gerry; Melin, Leif; Whittington, Richard (2003), Micro strategy and strategizing: Towards an activitybased view. Journal of Management Studies, 40(1), 3-22.

Kirzner, Israel M. (1973), Competition and entrepreneurship: University of Chicago Press. Chicago and London.

Knight, Frank H. (1921), Risk, uncertainty and profit. New York: Hart, Schaffner and Marx.

Kogut, Bruce; Zander, Udo (1992), Knowledge of the firm, combinative capabilities, and the replication of technology. Organization Science, 3(3), 383-397.

Kogut, Bruce; Zander, Udo (1996), What firms do? Coordination, identity, and learning. Organization Science, 7(5), 502-518.

Kuhn, Thomas S. (2012), The structure of scientific revolutions:University of Chicago press.

Latour, Bruno (2005), Reassembling the social: An introduction to actor-network-theory: Oxford university press. 
Lave, Jean; Wenger, Etienne (1991), Situated learning: Legitimate peripheral participation. New York: Cambridge University Press.

Lavie, Doven (2006), The competitive advantage of interconnected firms: An extension of the resource-based view. Academy of Management Review, 31(3), 638-658.

Liebeskind, Julia Porter (1996), Knowledge, strategy, and the theory of the firm. Strategic Management Journal, 17(2), 93-107.

Lippman, Steven Anderson; Rumelt, Richard P. (1982), Uncertain imitability: An analysis of interfirm differences in efficiency under competition. The Bell Journal of Economics, 418-438.

Mahoney, Joseph T.; Pandian, J. Rarajndran (1992), The resource-based view within the conversation of strategic management. Strategic Management Journal, 13(5), 363-380.

Makadok, Richard; Burton, Richard; Barney, Jay B. (2018), A practical guide for making theory contributions in strategic management. Strategic Management Journal, 39(6), 1530-1545.

Mantere, Saku (2013), What is organizational strategy? A language-based view. Journal of Management Studies, 50(8), 1408-1426.

March, James G.; Simon, Herbert A. (1958), Organizations, USA, Blackwell Business.

McKiernan, Peter (2017), Historical Evolution of Strategic Management, Volumes I and II: Routledge.

Meyer, John W.; Rowan, Brian (1977), Institutionalized organizations: Formal structure as myth and ceremony. American Journal of Sociology, 83(2), 340-363.

Mintzberg, Henry; Ahlstrand, Bruce; Lampel, Joseph (2001), Strategy Safari: A Guided Tour Through The Wilds of Strategic Mangament: Simon and Schuster.

Molina-Azorín, Jose F. (2014). Microfoundations of strategic management: Toward micro-macro research in the resource-based theory. Business Research Quarterly, 17(2), 102-114.

Nelson, Richard R.; Winter, Sidney G. (1982), An evolutionary theory of economic change. Harvard University, Cambridge, Massachusetts and London, England: The Belknap Press

Nonaka, Ikujiro (1994), A dynamic theory of organizational knowledge creation. Organization Science, 5(1), 14-37.

North, Douglas C. (1990), Institutions, institutional change and economic performance: Cambridge University Press.

Ocasio, William (1997), Towards an attention based view of the firm. Strategic Management Journal, 18(Summer Special Issue), 187-206.

Ocasio, William; Joseph, John (2005), An attention-based theory of strategy formulation: Linking micro-and macroperspectives in strategy processes. Strategy Process, 22, 39-61

Ocasio, William; Laamanen, Tomi; Vaara, Eero (2017), Communication and Attention Dynamics: An AttentionBased View of Strategic Change. Strategic Management Journal. 39(1), 155-167

Oliver, Christine (1997), Sustainable competitive advantage: Combining institutional and resource-based views. Strategic Management Journal, 18(9), 697-713.

Peng, Mike W. (2002), Towards an institution-based view of business strategy. Asia Pacific Journal of Management, 19(2-3), 251-267.

Peng, Mike W.; Sun, Sunny. Li.; Pinkham, Brian; Chen, Hao (2009), The Institution-Based View as a Third Leg for a Strategy Tripod. The Academy of Management Perspectives, 23(3), 63-81.

Penrose, Edith T. (1959), The Theory of the Growth of the Firm. Mansfield Centre, USA: Martino Publishing.

Peteraf, Margaret A. (1993), The cornerstones of competitive advantage: a resource-based view. Strategic Management Journal, 14(3), 179-191.

Polanyi, Michael (1962), Tacit knowing: It's bearing on some problems of philosophy. Reviews of Modern Physics, 34(4), 601-616.

Polanyi, Michael (1967), The tacit dimension. Garden City, NY: Anchor.

Porter, Michael E. (1980), Competitive startegy: Technigues for analyzing industies and competitors. New York: Free Press.

Porter, Michael E. (1981), The contributions of industrial organization to strategic management. Academy of Management Review, 6(4), 609-620. 
Porter, Michael E. (1989), How competitive forces shape strategy Readings in Strategic Management. Springer: 133-143.

Porter, Michael E. (1991), Towards a dynamic theory of strategy. Strategic Management Journal, 12(2), 95-117.

Porter, Michael E. (2008a), The five competitive forces that shape strategy. Harvard Business Review, 86(1), 78-93.

Porter, Michael E. (2008b), On competition: Harvard Business Press.

Porter, Michael E.; Spence, A. M. (1982), The capacity expansion process in a growing oligopoly: the case of corn wet milling The economics of information and uncertainty. University of Chicago Press: 259-316

Powell, Thomas C.; Lovallo, Dan; Fox, Craig R. (2011), Behavioral strategy. Strategic Management Journal, 32 (13), 1369-1386.

Priem, Richard L.; Butler, John E. (2001a), Is the resource-based "view" a useful perspective for strategic management research?. Academy of Management Review, 26(1), 22-40.

Priem, Richard L.; Butler, John E. (2001b). Tautology in the resource-based view and the implications of externally determined resource value: Further comments. Academy of Management Review, 26(1), 57-66.

Ramos-Rodríguez, Antonio-Rafael; Ruíz-Navarro, Jose (2004), Changes in the intellectual structure of strategic management research: A bibliometric study of the Strategic Management Journal, 1980-2000. Strategic Management Journal, 25(10), 981-1004.

Reckwitz, Andreas (2002), Toward a theory of social practices: A development in culturalist theorizing. European Journal of Social Theory, 5(2), 243-263.

Reed, Richard; Defilippi, Robert (1990), Causal ambiguity, barriers to imitation and sustainable advantage. Academy of Management Review, 15, 88-102.

Regnér, Patrick (2008), Strategy-as-practice and dynamic capabilities: Steps towards a dynamic view of strategy. Human Relations, 61(4), 565-588.

Ricardo, David (1821), On the principles of political economy and taxation (third edition edit.), Canada: Batoche Books.

Robinson, Joan (1933), Economics of imperfect competition. McMillian: ST Martin's Press.

Ronda-Pupo, Guillerimo Armando; Guerras-Martin, Luis Ángel (2012), Dynamics of the evolution of the strategy concept 1962-2008: A co-word analysis. Strategic Management Journal, 33(2), 162-188.

Salvato, Carlo; Vassolo, Roberto (2018), The sources of dynamism in dynamic capabilities. Strategic Management Journal, 39(6), 1728-1752.

Sarvan, Fulya; Arıcı, Eren Durmuş; Özen, Janset; Özdemir, Bahattin; İçigen, Ebru Tarcan (2003), On stratejik yönetim okulu: Biçimleşme okulunun bütünleştirici çerçevesi. Akdeniz Üniversitesi iiBF Dergisi, 6, 73-122.

Schulze, William S. (1994), The two schools of thought in resource-based theory: Definitions and implications for research. Advances in Strategic Management, 10(1), 127-152.

Schumpeter, Joseph Alois (1934), The theory of economic development: An inquiry into profits, capital, credit, interest, and the business cycle (R. Opie, Trans. Sixteenth ed.), New Brunswick (USA) and London (U.K.): Transaction Publishers.

Schumpeter, Joseph Alois (1942), Capitalism, Socialism and Democracy. London and New York: Taylor and Francis e-Library.

Shepherd, Dean A.; Mcmullen, Jeffrey S.; Ocasio, William (2017), Is that an opportunity? An attention model of top managers' opportunity beliefs for strategic action. Strategic Management Journal, 38(3), 626-644.

Simon, Herbert A. (1947), Administrative behavior. A study of decision-making processes in administrative organization: The Free Press, New York.

Spender, J. C.; Grant, Robert M. (1996), Knowledge and the firm: overview. Strategic Management Journal, 17(2), 5-9.

Teece, David J. (2007), Explicating dynamic capabilities: the nature and microfoundations of (sustainable) enterprise performance. Strategic Management Journal, 28(13), 1319-1350.

Teece, David J. (2014), The foundations of enterprise performance: Dynamic and ordinary capabilities in an (economic) theory of firms. Academy of management perspectives, 28(4), 328-352.

Teece, David J.; Pisano, Gary; Shuen, Amy (1997), Dynamic capabilities and strategic management. Strategic Management Journal, 18(7), 509-533. 


\section{Eskişehir Osmangazi Üniversitesi iiBF Dergisi}

Teece, David J.; Pisano, Gary (1994), The dynamic capabilities of firms: An introduction. Industrial and corporate change, 3(3), 537-556.

Wasserman, Stanley; Faust, Katherine (1994), Social network analysis: Methods and applications: Cambridge University Press.

Wernerfelt, Birger (1984), A resource-based view of the firm. Strategic Management Journal, 5(2), 171-180.

Whetten, David A.; Felin, Teppo; King, Brayden G. (2009), The practice of theory borrowing in organizational studies: Current issues and future directions. Journal of Management. 35(3), 537-563.

Whittington, Richard (1996), Strategy as practice. Long Range Planning, 29(5), 731-735.

Whittington, Richard (2006), Completing the practice turn in strategy research. Organization Studies, 27(5), 613634.

Williamson, Oliver E. (1975), Markets and Hierarchies: Analysis and antitrust implications. London: The Free Press: A Division of Macmillian Publishing Co., Inc.

Williamson, Oliver E. (1981), The economics of organization: The transaction cost approach. American Journal of Sociology, 87(3), 548-577.

Williamson, Oliver E. (1999), Strategy research: governance and competence perspectives. Strategic Management Journal, 20(12), 1087-1108.

Winter, Sidney G. (2003), Understanding dynamic capabilities. Strategic Management Journal, 24(10), 991-995.

Wittgenstein, Ludwig (1951), Philosophical investigations. John Wiley \& Sons.

Zollo, Maurizio; Winter, Sidney G. (2002), Deliberate learning and the evolution of dynamic capabilities. Organization Science, 13(3), 339-351. 


\section{Extended Summary}

\section{The Evolution of Strategic Management Researches: An Evaluation on Approaches and Micro Views}

This study seeks to answer the question "how strategic management research has evolved". Based on this question, an investigation was carried out within the framework of the approach and micro views that emerged in the strategic management literature. The approaches and micro-views are discussed in three groups: 1 . Positioning Approach (PA) (Porter, 1980, 1981), 2. Resource-Based Approach (RBA) (Barney, 1991; Wernerfelt, 1984) and 3. complementary views to RBA, which have effect on the historical development process of the strategic management field between 1980-2018.

In this classification, Resource-Based View (RBV) (Wernerfelt, 1984), Knowledge-Based View (KBV) (Grant, 1996a; 1996b), Dynamic Capabilities View (DCV) (Teece vd. 1997), and Relational View (RV) (Dyer ve Singh, 1998; Lavie, 2006) were discussed under RBA. In the group of the complementary views to RBA, explanations of the Strategy as A Practise (SAP) (Johnson vd., 2003; Whittington, 1996), Attention-Based View (ABV) (Ocasio, 1997; Ocasio ve Joseph, 2005) and Institution-Based View (IBV) (Peng, 2002; Peng vd. 2009) were based on. Thanks to this classification, micro views scattered in the field were gathered and categorized in a frame and an important step was taken in order to eliminate the mess in the field

The investigation was conducted as a systematic literature review (Molina Azorin, 2014) and according to the chronological order of approaches and micro views. The systematicity refers to the criteria used to evaluate the approach and micro views. In this context, the following criteria were used to frame the study: (1) Theoretical foundations (2) competitive advantage bases and (3) sustainability mechanisms of approaches and micro views. The study conducted around these criteria provided information about the evolution patterns of strategic management research. Therefore, this study aimed to clarify the distinction between the mentioned approach and micro views by making a comparison about the theoretical foundations, basic concepts and assumptions of each approach and micro views in the evolution of the strategic management discipline, and their explanations on the bases of competitive advantage and the sustainability mechanisms. In this way, a more refined framework regarding the approach and micro views that can be considered as important building blocks in the evolution of the discipline was presented. This contribution to the literature was important, because it showed the similarities and nuances between the overlapping explanation patterns that emerge as a new view and / or approach each day within the discipline.

The first criterion considered in the examination is the theoretical basis of each approach and micro view. Due to the eclectic nature of the strategic management field, it was observed that the approaches and micro views in the field used concepts, assumptions and theories from different disciplines. These disciplines included economics, sociology, psychology, biology and politics. This situation shows up with the theories brought to the field by these disciplines. In this regard, the theoretical foundations on which approaches and micro views were based are as follows:

- PA feeds on Structure Conduct Performance (SCP) Paradigm;

- $\quad$ Under RBA; RBV feeds on Chicago school; KBV feeds on the Theory of the Growth of the Firm, Austrian School of Economics, Evolutionary Economic Theory, Organizational Learning Theory; DCV feeds on The Theory of the Growth of the Firm, Evolutionary Economic Theory, Austrian School of Economics, Social Network Theory, Transaction Cost Theory, Behavioral Theory of the Firm, Behavioral Decision Theory; RV feeds on Social Network Theory.

- From micro complementary views of RBA, SAP feeds on The learning theory, Behavioral Theory of the Firm, actor-network theory, institutional theory; ABV feeds on behavioral decision theory; IBV feeds on behavioral decision theory and new institutional economies.

It was seen that the micro views based on different theoretical foundations attempted to explain strategic phenomenons at different analysis levels (micro-macro) and by means of different variables (internal and external). The examined micro views addressed macro analysis-level phenomenons such as resources, capabilities, alliances, joint ventures, markets, industries, institutions, nations, and micro analysis-level phenomenons such as individuals and relationships between individuals. Different analysis levels contribute to the efficiency of the strategic management field and bring different theories to the field. However, progress made on the basis of different theories paves the way for changes in the field of hypotheses. These hypothetical changes were seen generally in the RBV literature (Foss and Hallberg, 2016: 4-5; Bağış and Hızıroğlu, 2017: 19) and particularly in the literature on dynamic capabilities (Salvato and Vassolo, 2018). This also lead to inconsistencies on the theoretical foundations and risk of fragmentation in that field. Once again, this theoretical pluralism makes the boundaries of the field uncertain. While this uncertainty provides a 
positive momentum in the development, production and dynamism of the field, it creates diversity and disorganization in scientific knowledge. It causes the knowledge in this field to become more blurred and provides a rationale for this study.

The second criteria is the bases of the competitive advantage. The approach and micro views explains the bases of the competitive advantage as follows:

- PA considers operating in an attractive industry and achieving a competitive position in the industry as the basis of its competitive advantage.

- Under RBA; the bases of competitive advantage are as follows; obtaining resources from strategic factor markets and holding them according to RBV; the efficiency, scope and flexibility of integration that ensures the organization of information within the firm, the according to KBV; organizational capabilities shaped by firm-specific assets and evolutionary processes according to DCV; investments in relation-specific assets, inter-company information exchange routine, complementary resource variety and effective governance mechanisms according to RV.

- Within the scope of views complementary to RBA; SAP sees routines; IBV sees the ability to manage the institutional context (normative rationality, institutional isolation mechanisms and uniformity pressures) as the basis of competitive advantage. However, ABV focuses on behaviors of the firm rather than explanations regarding the bases of competitive advantage.

The third criteria considered in the examination of the strategic management field is the sustainability mechanisms. The approach and micro views explain the sustainability mechanisms as follows:

- $\quad$ PA emphasizes entry barriers to ensure the sustainability of the competitive advantage achieved.

- It is seen that all the four views under RBA mainly focus on imitation barriers in terms of sustainability mechanisms. In this regard, the bases of sustainability mechanisms are rare, valuable, difficult-to-imitate and substitute resources according to RBV; inimitable implicit knowledge according to KBV; inimitable organization capabilities according to DCV; relation-specific imitation barriers according to $\mathbf{R V}$.

- Within the scope of the micro views complementary to RBA, while ABV makes no explanation, $\mathbf{R B V}$ and IBV focuses on the necessity of imitation barriers likewise micro views under RBA. In this regard, sustainability is ensured by difficult-to-imitate routines according to RBA and by the firm's value adding resources and capabilities and contextual factors to ensure the efficiently utilization of these resources and capabilities according to IBV.

In summary, while PA points out an attractive industry and achieving a competitive position in that industry as the basis of competitive advantage, both views under RBA and those complementary to RBA emphasizes resources and capabilities. As sustainability mechanism, PA focuses on entry barriers to market, while both views under RBA and those complementary to RBA focus on inimitable resources, routines, capabilities and alliances. 